\title{
Tailor-made generation of insulin-producing cells from canine mesenchymal stem cells derived from bone marrow and adipose tissue
}

\section{Watchareewan Rodprasert}

Inter-Disciplinary Program of Pharmacology, Graduate School, Chulalongkorn University, Bangkok

\section{Sirirat Nantavisai}

Veterinary Pharmacology and Stem Cell Research Laboratory, Veterinary Stem Cell and Bioengineering Innovation Center (VSCBIC), Faculty of Veterinary Science, Chulalongkorn University, Bangkok

\section{Koranis Pathanachai}

Department of Pharmacology, Faculty of Veterinary Science, Chulalongkorn University, Bangkok

\section{Prasit Pavasant}

Department of Anatomy and Center of Excellence for Regenerative Dentistry, Faculty of Dentistry, Chulalongkorn University, Bangkok

\section{Thanaphum Osathanon}

Department of Anatomy and Center of Excellence for Regenerative Dentistry, Faculty of Dentistry, Chulalongkorn University, Bangkok

Chenphop Sawangmake ( $\square$ chenphop@gmail.com )

Veterinary Stem Cell and Bioengineering Research Unit, Faculty of Veterinary Science, Chulalongkorn University, Bangkok

\section{Research Article}

Keywords: diabetes, insulin-producing cell (IPC)

Posted Date: December 10th, 2020

DOl: https://doi.org/10.21203/rs.3.rs-119640/v1

License: (c) (i) This work is licensed under a Creative Commons Attribution 4.0 International License. Read Full License 
Tailor-made generation of insulin-producing cells from canine mesenchymal stem cells derived from bone marrow and adipose tissue

Watchareewan Rodprasert ${ }^{1,2,3,5}$, Sirirat Nantavisai ${ }^{2,3}$, Koranis Pathanachai $^{2,3,5}$, Prasit Pavasant ${ }^{4}$, Thanaphum Osathanon ${ }^{4}$, Chenphop Sawangmake $e^{2,3,5, *}$

${ }^{1}$ Inter-Disciplinary Program of Pharmacology, Graduate School, Chulalongkorn University, Bangkok, THAILAND

${ }^{2}$ Veterinary Pharmacology and Stem Cell Research Laboratory, Veterinary Stem Cell and Bioengineering Innovation Center (VSCBIC), Faculty of Veterinary Science, Chulalongkorn University, Bangkok, THAILAND

${ }^{3}$ Veterinary Stem Cell and Bioengineering Research Unit, Faculty of Veterinary Science, Chulalongkorn University, Bangkok, THAILAND

${ }^{4}$ Department of Anatomy and Center of Excellence for Regenerative Dentistry, Faculty of Dentistry, Chulalongkorn University, Bangkok, THAILAND

${ }^{5}$ Department of Pharmacology, Faculty of Veterinary Science, Chulalongkorn University, Bangkok, THAILAND

*e-mail: chenphop.s@chula.ac.th, chenphop@gmail.com 


\begin{abstract}
Trend of regenerative therapy for diabetes in human and veterinary practice has conceptually been proven according to Edmonton protocol and animal models. Establishing an alternative insulin-producing cell (IPC) resource is a challenge task for further clinical application. In this study, IPC generation from two practical canine mesenchymal stem cells (cMSCs), canine bone marrow-derived MSCs (cBM-MSCs) and canine adipose-derived MSCs (cAD-MSCs), was of interest. The results illustrated that cBM-MSCs and cAD-MSCs contained distinct pancreatic differentiation potential and required the tailor-made induction protocols. Effective generation of cBM-MSC-derived IPCs needed an integration of genetic and microenvironment manipulation using hanging-drop culture of $P D X-1$-transfected cBM-MSCs under three-step pancreatic induction protocol. However, this protocol was resource- and timeconsumed. Another study on cAD-MSC-derived IPC generation found that IPC colonies could be obtained by low attachment culture under three-step induction protocol. Further Notch signaling inhibition during pancreatic endoderm/progenitor induction yielded IPC colonies with trend of glucose-responsive C-peptide secretion. Thus, this study showed that IPCs could be obtained from cBM-MSCs and cAD-MSCs by different induction techniques, and further signaling manipulation study should be conducted to maximize the protocol efficiency.
\end{abstract}




\section{Introduction}

Diabetes is not only a major metabolic disease affecting people around the world, but also the companion animals, mostly dogs and cats ${ }^{1-3}$. By pathophysiological basis, it is classified into 2 main types, type I and II, as characterized by absenting or presenting of intact beta-cells, respectively ${ }^{2,4}$. Type I diabetes is referred to an immune-mediated beta-cell destruction causing endogenous insulin depletion, while type II is related to insulin secretion defect and/or insulin resistance ${ }^{1,4}$. Although, diabetes treatment seems well-established, adverse events and compromised clinical efficiency have been periodically reported ${ }^{3,5}$. Trend of regenerative treatment has been introduced for addressing these issues starting from cadaveric islet transplantation in diabetes type I patients, namely "Edmonton protocol", which resulted in long-term omitting of exogenous insulin administration ${ }^{6-8}$. However, two main obstacles have been suggested, donor shortages and immunosuppressants' side effects, making stem cell (SC)based regenerative approach be the potential clinical candidate ${ }^{6-9}$.

Concept of SC-derived insulin-producing cell (IPC) transplantation for treating diabetes has been conceptually approved in animal models. However, it comes with further challenges on finding potential candidate cell sources and establishing efficient IPC production platforms that are clinically applicable ${ }^{10-12}$. Although, the study on IPC production using human SCs has widely been studied and well-established, the knowledge in IPC generation aiming for veterinary application is still lacking. It has been a few reports suggesting the induction of canine somatic cells and canine mesenchymal MSCs (cMSCs) toward IPCs in vitro ${ }^{13,14}$. These generated IPCs were formed as cell aggregates attached to culture surface that might cause some difficulties during cell harvesting and processing for transplantation. To earn the clinical applicable IPCs, three-dimensional (3D) structure of IPCs floating or suspending in culture vessels would be 
required to ease the harvesting and encapsulating processes ${ }^{15}$. To address this issue, the integrative induction protocols aiming for the pancreatic differentiation of canine bone marrowderived MSCs (cBM-MSCs) and canine adipose-derived MSCs (cAD-MSCs) were established in this study. The protocols were aimed for the delivery of 3D colony structure of the generated IPCs. Notch signaling manipulation was additionally conducted in the potential protocol for maximizing the induction efficiency. The results will be the crucial platform supporting the IPC generation which eventually benefits the establishment of clinical protocols for both veterinary and human applications.

\section{Results}

\section{cBM-MSC and $c A D$-MSC characterization}

The isolated cBM-MSCs (Figure 1A and B) and cAD-MSCs (Figure 1C and D) showed fibroblast-like appearance upon 2D culture. mRNA expression of stemness-related markers (Rexl and Oct4) and proliferation marker (Ki67) were detected (Figure 1E and F). MSC-related surface marker analysis by flow cytometry showed that both cells contained high proportion of $\mathrm{Cd} 90^{+}$cells, while the proportion of $\mathrm{Cd} 73^{+}$cells was relatively low. The expression of hematopoietic surface marker (Cd45) was considered absent in both cells (Figure $1 \mathrm{G}$ and $\mathrm{H}$ ).

Both cells illustrated the in vitro osteogenic differentiation potential upon the 14-day induction protocol regarding ECM mineralization as demonstrated by Alizarin Red S and Von Kossa staining (Figure 1I and J) and osteogenic mRNA marker expression (Alp, Runx2, Osx, Opn, Ocn, and Collal) (Figure 1K and L).

The results revealed the MSC-related characteristics of the isolated cBM-MSCs and cAD-MSCs. 


\section{Generation of IPCs from cBM-MSCs requires 3D culture condition}

To generate IPC colonies from cBM-MSCs, three different culture techniques were investigated (Figure 2A-C). In all culture techniques, three pancreatic induction media were used as a microenvironmental manipulating/small molecule inducing approach. The results as illustrated in Figure 2D showed that suspending the cells in low attachment culture dish (Protocol I) was unable to deliver IPC colonies, while maintaining the cells using hanging-drop technique (Protocol II) could successfully generate IPC colonies with 50-200 $\mu \mathrm{m}$ in diameter. However, the colonies seemed loose cell aggregates. Further investigation was performed by maintaining the colonies collected from hanging-drop culture in Matrigel ${ }^{\circledR}$-embedded culture condition (Protocol III). Although, the generated colonies were dense and compact, they could not maintain colony structure after gel digestion using Cell Recovery Solution ${ }^{\circledR}$ making them unable to be harvested for further functional testing.

Comparison of the pancreatic mRNA markers of the generated IPC colonies revealed that colonies from Protocol II expressed high pancreatic endoderm marker $(P d x I)$, but low pancreatic beta-cell markers (Nkx-6.1, Isl-1, Glut-2, and Insulin), comparing with those from Protocol III (Figure 2E and F). However, the mRNA expression of pancreatic-relating markers (Glucagon and Glplr) was not detected in Protocol III (Figure 2G).

Further functional testing showed that IPC colonies collected from Protocol II secreted C-peptide under basal condition but could not produce a significant response upon low (5.5mM) and high $(22 \mathrm{mM})$ glucose stimulation. There was only trend of increased C-peptide secretion compared to basal control (Figure 2H). 
Thus, generating IPCs from cBM-MSCs by microenvironmental manipulating/small molecule inducing approach required 3D culture condition. However, the generated IPCs showed limited function and maturity.

\section{Overexpression of PDX1 fails to generate IPCs from cBM-MSCs}

Further generating IPCs from cBM-MSCs using genetic manipulating approach was conducted by overexpression of the pancreatic commitment regulator, $P D X 1$. Lentiviral vector carrying PDX1 was transfected into cBM-MSCs at MOI 20, 30, and 50 (Figure 3A). The results showed that all transfected cells started forming loose cell aggregates since 48-hour posttransfection. Then, at 168-hour post-transfection, transfected cells at MOI 20 formed small-size cell clusters $(<50 \mu \mathrm{m}$ in diameter), while those transfected at MOI 30 and 50 formed mediumto large-size cell clusters $(100-200 \mu \mathrm{m}$ in diameter). None of them formed floating colony-like structure (Figure 3B).

Further analysis on pancreatic mRNA markers showed that transfected cells at MOI 20 significantly illustrated high expression of pancreatic endoderm marker $(P d x l)$ and some of pancreatic beta-cell markers (Maf-A, Glut-2, and Insulin), comparing with those transfected at MOI 30 and 50 (Figure 3C and D). However, alpha-cell hormonal marker (Glucagon) was significantly expressed in MOI 20 transfection (Figure 3E), while Glplr was not detected in all groups.

The results suggested that overexpression of $P D X 1$ could not successfully generate IPC colonies from cBM-MSCs in terms of pancreatic islet morphology and genotype. 
Integration of PDX1 overexpression with 3D culture effectively generates IPCs from cBMMSCs

In order to effectively generate IPCs from cBM-MSCs, combination of genetic and microenvironmental manipulating approaches was used. Cells were transfected with lentiviral vector carrying human $P D X 1$ at MOI 20 then maintained with three-step induction protocol under 3D culture condition (hanging-drop technique) (Figure 4A). The results illustrated that IPC colonies started forming since day 5 of the induction, and size of colonies at day 12 was approximately 100-200 $\mu \mathrm{m}$ (Figure 4B).

Pancreatic mRNA analysis showed that pancreatic endoderm marker $(P d x I)$ and pancreatic beta-cell markers (Isl-1, Maf-A, Glut-2, and Insulin) were significantly upregulated (Figure 4C and D). However, alpha-cell hormonal marker (Glucagon) was highly expressed (Figure 4E), while Glplr was not detected. Functional testing also showed that IPC colonies secreted C-peptide under basal condition, but they could not produce a dose-dependent response upon low (5.5mM) and high (22mM) glucose stimulation (Figure 4F).

Thus, combination of genetic and microenvironmental manipulating approaches effectively generated IPCs from cBM-MSCs with high pancreatic mRNA marker expression along with the ideal islet morphology. However, their functional property was still limited.

\section{Low attachment culture is efficient to generate IPCs from cAD-MSCs}

To generate IPCs from cAD-MSCs, microenvironmental manipulating approach was used by suspending the cells onto low attachment culture dishes and maintaining in three-step induction media (Figure 5A). It was quite interesting that cells formed colony-like structure since day 3 of the induction, and the colonies became denser and bigger along the culture period 
(Figure 5B). At day 12, approximately 834 colonies (median) were obtained from $1 \times 10^{6}$ seeding cells (Figure 5C), and the colony size was varied from $<50 \mu \mathrm{m}$ to $>700 \mu \mathrm{m}$ (Figure 5D).

Analysis of pancreatic mRNA expression revealed that pancreatic beta-cell markers (Nkx-6.1, Isl-1, Maf-A, Glut-2, and Insulin) were significantly upregulated (Figure 5E). Alphacell hormonal marker (Glucagon) was a bit expressed, while Glplr was downregulated (Figure 5F). Functional testing showed that IPC colonies secreted C-peptide under basal condition and showed trend of glucose-responsive C-peptide secretion upon high (22mM) glucose stimulation. However, it was not statistically significant compared to basal secretion (Figure 5G).

The results suggested that microenvironmental manipulating approach using low attachment culture was efficient to generate IPCs from cAD-MSCs in term of pancreatic islet characteristics. However, their functional property was still limited.

\section{Notch signaling optimization generates potential cAD-MSC-derived IPCS}

According to the results of IPC induction protocol efficiency, it has been suggested that generation of cAD-MSC-derived IPCs using microenvironmental manipulating approach seemed the most efficient protocol in terms of 1) morphological appearance and colony number, 2) pancreatic mRNA marker expression, and 3) functional property. In this regard, Notch signaling optimization was performed for generating the potential cAD-MSC-derived IPCs using protocol mentioned in our previous report ${ }^{16}$.

cAD-MSC-derived IPCs were generated using optimized three-step induction protocol (Figure 6A) with Notch signaling manipulation using gamma-secretase inhibitor, DAPT, during definitive endoderm induction (DAPT-A) (Figure 6B) or pancreatic endoderm/progenitor induction (DAPT-B) (Figure 6C). The results showed that, in all conditions, cells started colony 
formation since day 3 post-induction, then colony size and number were increased during the induction period (Figure 6D). Total colony counts (median) were 834, 691.5, and 504 colonies per batch $\left(1 \times 10^{6}\right.$ seeding cells) for control, DAPT-A, and DAPT-B, respectively (Figure 6E). It seemed that DAPT-B delivered more proportion of small-size colony ( $<50 \mu \mathrm{m}$ and $50-100 \mu \mathrm{m})$, but statistical difference was not recognized due to variation among groups (Figure 6F).

Pancreatic mRNA analysis illustrated that cAD-MSC-derived IPCs from DAPT-B condition significantly showed lesser degree of pancreatic endoderm marker $(P d x l)$ and pancreatic beta-cell markers (Isl-1, Maf-A, Glut-2, and Insulin), comparing with those from DAPT-A condition (Figure 7A and B). However, alpha-cell hormonal marker (Glucagon) of DAPT-B group was much lower than that in DAPT-A group. Glp1r was downregulated in all conditions (Figure 7C). Interestingly, analysis of Notch target genes, Hes-1 and Hey-1, showed that DAPT-B group showed significant upregulation of both genes comparing with others (Figure 7D). Functional testing showed that cAD-MSC-derived IPCs from DAPT-B condition yielded highest basal C-peptide secretion as well as the higher glucose-responsive C-peptide secretion upon low $(5.5 \mathrm{mM})$ and high $(22 \mathrm{mM})$ glucose stimulation, comparing with control and DAPT-A groups. It should be noted that, due to variation within group, statistical difference within each group was not found (Figure 7E).

Taken together, the results suggested that cAD-MSC-derived IPCs could be efficiently generated using microenvironmental manipulating approach with Notch optimization. The obtained IPCs from Notch inhibition during pancreatic endoderm/progenitor induction showed pancreatic islet/beta-cell characteristics and positive trend of functional property. 


\section{Discussion}

As the proof-of-concept evidences for treating diabetes by regenerative therapy have been reported in human and animal models ${ }^{9,17-20}$, MSCs have been proposed as one of the promising resources for generating clinical applicable IPCs ${ }^{21-24}$. In this study, the pancreatic differentiation potential of cBM-MSCs and cAD-MSCs was evaluated aiming for determining the feasibility of IPC formation in vitro and the potential of their clinical application. The cBMMSCs and cAD-MSCs were isolated, cultured, and expanded using previous published protocols 25-28. Their characteristics were similar as described in previous reports including fibroblast-like structure, mRNA expression related to stemness and proliferation, MSC-related surface marker expression, and osteogenic differentiation potential ${ }^{26-30}$. It should be noted that the expression of Cd73 in both MSCs was relatively low as mentioned in previous report ${ }^{31}$. This evidence supported the consistency of the cMSCs' properties used in this report.

In term of IPC formation in vitro, various protocols employing either microenvironmental manipulation or genetic manipulation have been reported ${ }^{11,32-36}$. The strategies used in these studies usually relied on origin and pluripotency/multipotency of the cells 37-41. It should be noted that pluripotent SCs, ESCs and iPSCs, contained high capability of pancreatogenesis in vitro ${ }^{42-47}$. However, due to their ethical and safety concerns, MSCs have been proposed as an alternative source for IPC generation $10,11,17,33,46,48-50$.

Here, we illustrated that cBM-MSCs and cAD-MSCs could be differentiated toward pancreatic lineage in vitro. However, each cell type contained different pancreatic differentiation potential and required a tailor-made induction technique. For IPC generation by cBM-MSCs, it has been shown that microenvironmental manipulating approach with low attachment culture (2D culture) could not produce an islet-like cell aggregate in vitro, but it required 3D culture 
technique for generating and maintaining the colony-like structure of IPCs. By using hangingdrop culture technique, cBM-MSCs formed cell aggregates since day 3 post-induction, then size of the colony was increased along with the expression of pancreatic mRNA markers. Further experiment showed that Matrigel ${ }^{\circledR}$-embedded culture of the colonies derived from hanging-drop culture could give a dense colony structure and higher levels of pancreatic marker expression.

Previous publications reported that small molecule induction could imitate the environment during pancreatic endocrine development ${ }^{10,16,43,51-56}$. Generally, an in vitro pancreatic differentiation from SCs could be categorized into 6 differentiation stages: pluripotent/multipotent SCs, mesendoderm, definitive endoderm, pancreatic endoderm, pancreatic endocrine, and pancreatic beta-cells/IPCs ${ }^{15,57}$. In this study, activin A was used to mimic the effects of endogenous noggin for shortcutting the definitive endoderm establishing step as described in previous reports ${ }^{32,57-62}$. It was quite interesting that maintaining cBM-MSCs with pancreatic induction media in low attachment culture was unable to form colony-like structure which is the natural pancreatic islet topology and crucial for an in vitro pancreatic differentiation ${ }^{16,32,59,63-65}$. Therefore, the 3D culture condition using hanging-drop and Matrigel $^{\circledR}$-embedded culture techniques were used for generating the cBM-MSC-derived IPC colony. It has been shown that hanging-drop culture was an efficient technique for embryoid body/cell colony formation in vitro ${ }^{66-69}$ along with the natural/synthetic hydrogel-embedded culture that was one of the effective culture techniques used for organoid formation and expansion ${ }^{70-74}$. In this study we demonstrated the successful IPC colony formation by these two culture techniques. However, it was quite difficult to collect and expand the IPC colonies since colony maintaining and medium changing for hanging-drop culture were time-consumed. In addition, treating the Matrigel ${ }^{\circledR}$-embedded colonies with hydrogel digesting solution (Cell 
Recovery Solution ${ }^{\circledR}$ ) caused colony dissociation. Further functional assay could only be performed for IPC colonies derived from hanging-drop culture and found that the obtained IPC colonies could basally secrete C-peptide but not a significant response to glucose stimulation. Additional genetic manipulating approach was performed and showed that overexpression of PDXI at MOI 20 could enhance pancreatic beta-cell marker expression but was unable to produce 3D IPC colony.

These findings led to the integration of genetic and microenvironment manipulating approaches by hanging-drop culture of $P D X 1$-transfected cBM-MSCs under three-step induction cocktails. The results demonstrated the effective formation of 3D IPC colonies with significant pancreatic marker expression along with the basal C-peptide secretion. Our findings were correlated to previous reports showing that $P D X I$ was an essential gene in the first hierarchy of pancreatic organogenesis progressing toward beta-cell maturation ${ }^{57,75}$. PDXI-positive cells were considered as the pancreatic progenitors for three pancreatic lineages, comprising endocrine, exocrine, and ductal cells ${ }^{10}$. It has been shown that the overexpression of $P D X I$ by lentiviral vector into mouse MSCs could enhance IPC generation by triggering the morphological change from adherent spindle fibroblast-like cells toward the ball-like cell colonies ${ }^{33,76}$. For cBMMSCs, we found that 3D culture condition was required to form the IPC colony which was considered as the native pancreatic islet morphology ${ }^{35,63,65,77}$. Thus, cBM-MSC-derived IPCs were able to obtain from the integrating protocol of genetic and microenvironmental manipulation. However, hanging-drop 3D culture technique was time- and labor-consumed, making it less clinical applicable.

Alternatively, cAD-MSCs have been proposed as the potential MSC candidate for regenerative diabetes therapy as mentioned in previous reports ${ }^{18,51,76,78-80}$. We showed in this 
study that cAD-MSC-derived IPC colonies could efficiently be generated from low attachment culture with the expression of crucial pancreatic mRNA markers. Functional assay showed a basal C-peptide release with trend of glucose-responsive c-peptide secretion in high glucose (22 $\mathrm{mM}$ ) stimulation. Our finding was correlated with previous studies on the generation of pancreatic progenitors (PPs) and IPCs by AD-MSCs derived from human and animal resources $32,51,52,79,81$. Most of the IPC induction protocols used for AD-MSC induction relied on the concept of microenvironmental induction which reflect the trans-lineage differentiation potential of the cells ${ }^{32,51,79,80}$. In 2006, Timper et al. had initially proved the prospect of human AD-MSCs (hAD-MSCs) toward IPCs using a single step microenvironmental manipulating approach ${ }^{80}$. After that, Chandra et al. published a three-step microenvironmental manipulating protocol for inducing murine AD-MSCs (mAD-MSCs) toward islet-like cell aggregates (ICAs) ${ }^{32}$. mADMSCs could be successfully committed toward each stage of pancreatic endocrine development regarding definitive endoderm, pancreatic endoderm, and pancreatic endocrine precursor as illustrated by the upregulating pancreatic markers in each stage. These findings supported the pancreatic differentiation potential of AD-MSCs derived from various species.

It has been suggested that the promising regenerative therapy for diabetes relies on the availability and the potential of stem cells used for generating PPs or IPCs, the efficiency of induction protocol, and the potential application on further established transplantation platform. One of the potential transplantation platforms is cell or colony encapsulation which requires the 3D colony structure of the IPCs that can be harvested after an in vitro production. This encapsulation platform can support and immobilize IPC colonies with the immunoisolating property against host immunity ${ }^{15}$. By comparing the potential clinical application, it seemed that 
cBM-MSC-derived IPCs showed less potential due to the complicated and time/labor-consumed induction protocol. Therefore, cAD-MSC-derived IPCs were further optimized.

Various factors and signaling have been studied for the potential effects on IPC generation in vitro. In this regard, Notch signaling was of interest due to its significant effect during pancreatogenesis both in vivo and in vitro ${ }^{82-85}$. cAD-MSC-derived IPCs were generated using optimized three-step induction protocol with Notch signaling manipulation by gammasecretase inhibitor, DAPT, during definitive endoderm or pancreatic endoderm/progenitor induction. We found that Notch inhibition during pancreatic endoderm/progenitor induction benefited the cAD-MSC-derived IPC production in terms of high basal C-peptide secretion and positive trend of glucose-responsive C-peptide secretion. These findings were correlated with previous studies that Notch signaling played a biphasic role in pancreatogenesis during embryonic development. Downregulation of Notch is required for pancreatic endoderm commitment and $P d x l$-postive pancreatic precursor expansion, while Notch upregulation is crucial for late-state pancreatic maturation ${ }^{84-86}$. Our previous study also showed that inhibition of Notch during pancreatic endoderm induction by human dental pulp stem cells (hDPSCs) resulted in high number of IPC colony production with high expression of $P D X 1$, whereas the inhibition during maturation stage caused the impairment of glucose-responsive C-peptide secretion ${ }^{16}$.

During pancreatogenesis, endocrine precursors formed clusters which allowed cell-to-cell contact and the interaction so called "lateral inhibition". This led to the activation of Notch signaling and the regulation of endocrine fate descended from $P d x 1$-positive progenitors ${ }^{87-89}$. Previous studies have confirmed the involvement of Notch signaling during endocrine progenitor fate commitment toward one of pancreatic endocrine subtypes (beta- or alpha-cells) ${ }^{89-91}$. The 
inhibition of Notch by HES1 shRNA could induce the redifferentiation of expanded human betacell-derived cells following with the significant expansion of beta-cell in vitro and the upregulation of beta-cell-related genes ${ }^{92}$. However, overactivation of Notch could limit the differentiation capability toward fully matured IPCs by inhibiting the expression of "predifferentiation" gene by pancreatic progenitors ${ }^{93}$. These evidences also supported our findings that the cAD-MSC-derived IPCs could be generated in vitro, and the selective Notch signaling manipulation played the beneficial roles on colony production, pancreatic marker expression, and functional property.

\section{Conclusion}

In conclusion, we illustrated that cMSC-derived IPCs could be generated from cBMMSCs and cAD-MSCs in vitro. However, these two cMSCs contained different pancreatic differentiation potential and required specific induction techniques. Further studies focusing on maturation and transplantation platform will fulfill the production of clinical applicable cMSCderived IPCs.

\section{Materials and Methods}

\section{Cell isolation, culture, and expansion}

All protocols were conducted in accordance with guidelines and regulations approved by the Institutional Animal Care and Use Committee (IACUC), Faculty of Veterinary Science, Chulalongkorn University (Animal Use Protocol No.1531072). cMSCs were isolated from bone marrow and fat tissue of healthy dogs according to the inclusion criteria. Informed Consent was taken from pets' owners for inclusion of dogs in the study. cBM-MSCs were isolated from 
heparin-containing bone marrow aspirate following our previous published protocol ${ }^{28}$. Briefly, cells were washed with Hank's Balanced Salt solution (HBSS) (Thermo Fisher Scientific Corporation, USA), then resuspended with high glucose Dulbecco's Modified Eagle Medium: Nutrient Mixture F-12 (DMEM /F-12) (Thermo Fisher Scientific Corporation) supplemented with $10 \%$ fetal bovine serum (FBS) (Thermo Fisher Scientific Corporation), 1\% GlutaMAX (Thermo Fisher Scientific Corporation), and 1\% Antibiotics-Antimycotic (Thermo Fisher Scientific Corporation).

cAD-MSCs were isolated from biopsied adipose tissues. Tissues were minced and incubated with Cell Recovery Solution ${ }^{\circledR}$ (Corning, USA) for 2 hours at $37^{\circ} \mathrm{C}$, then passed through $70 \mu \mathrm{m}$ strainer and washed twice with PBS. Pellet was resuspended and seeded onto culture containers. Cells were maintained in high glucose DMEM (Thermo Fisher Scientific Corporation) supplemented with 10\% FBS, 1\% GlutaMAX ${ }^{\mathrm{TM}}$, and 1\% Antibiotics-Antimycotic.

Both cell types were maintained at $37^{\circ} \mathrm{C}$ in humidified atmosphere with $5 \% \mathrm{CO}_{2}$ and fresh air. Culture media was replaced every 48 hours. Cells were subcultures when $80 \%$ confluence reached. Cells in passage 2-6 were used for the experiments.

\section{Characterization of cBM-MSCs and $c A D-M S C s$}

The isolated cells were characterized by assessing mRNA expression regarding stemness markers (Rexl and Oct4) and proliferative marker (Ki67) by reverse transcription-quantitative polymerase chain reaction (RT-qPCR). MSC-related and hematopoietic surface markers were analyzed by flow cytometry. Cells were stained with mouse anti-Cd73 monoclonal antibody (Invitrogen, USA) and FITC-conjugated goat anti-mouse immunoglobulin (Ig) G secondary antibody (BioRad, USA), PE-conjugated rat anti-Cd90 monoclonal antibody (eBioscience, USA), 
and FITC-conjugated mouse anti-Cd45 monoclonal antibody (BioLegend, USA). Mouse IgG Isotype (BioLegend), PE-conjugated rat IgG Isotype (BioLegend), and FITC-conjugated mouse IgG Isotype (BioLegend) were used as isotype control. FACScallibur flow cytometer with CellQuest software (BD Bioscience) was used for analysis.

Cell differentiation potential was assessed using osteogenic induction protocol. Briefly, cells were seeded onto 24-well culture plate (Corning, USA) in a concentration of $2.5 \times 10^{5}$ cells/well. After 24 hours, cells were maintained in osteogenic induction medium for 14 days. The osteogenic induction medium was a growth medium supplemented with $50 \mathrm{mg} / \mathrm{mL} \mathrm{L}$ ascorbic acid, $100 \mathrm{mM}$ dexamethasone, and $10 \mathrm{mM} \beta$-glycerophosphate ${ }^{16}$. Osteogenic differentiation potential was analyzed according to extracellular matrix (ECM) mineralization by Alizarin Red $\mathrm{S}^{94}$ and Von Kossa staining ${ }^{95}$, and osteogenic-related mRNA marker expression (Alp, Runx2, Osx, Opn, Ocn and Colla1) by RT-qPCR. Undifferentiated cells were used as control.

\section{IPC induction by microenvironmental manipulation}

In this regard, three-step induction protocol modified from previous published reports was used ${ }^{16,32,59}$. Briefly, cells were trypsinized and resuspended in a series of three pancreatic induction media, namely serum-free medium (SFM)-A, SFM-B, and SFM-C, respectively. Cells were consequently maintained in SFM-A for 3 days (72 hours), SFM-B for 2 days (48 hours), and SFM-C for 5 days (120 hours). SFM-A was SFM-DMEM/F12 or SFM-DMEM (basal medium) supplemented with $1 \%$ bovine serum albumin (BSA, Cohn fraction V, fatty acid free) (Sigma-Aldrich, USA), 1X insulin-transferrin-selenium (ITS) (Invitrogen), $4 \mathrm{nM}$ activin A (Sigma-Aldrich), $1 \mathrm{nM}$ sodium butyrate (Sigma-Aldrich), and $50 \mu \mathrm{M}$ beta-mercaptoethanol 
(Sigma-Aldrich). SFM-B was basal medium supplemented with 1\% BSA, 1X ITS, and $0.3 \mathrm{mM}$ taurine (Sigma-Aldrich). SFM-C was basal medium containing 1.5\% BSA, 1X ITS, 3 mM taurine, $100 \mathrm{nM}$ glucagon-like peptide (GLP)-1 (Sigma-Aldrich), $1 \mathrm{mM}$ nicotinamide (SigmaAldrich), and $1 \mathrm{X}$ non-essential amino acids (NEAAs) (Sigma-Aldrich). Gamma-secretase inhibitor (DAPT) was used in some experiments at $25 \mu \mathrm{M}$.

Regarding culture maintenance, three different techniques were employed: low attachment, hanging-drop, and hydrogel $\left(\right.$ Matrigel $\left.^{\circledR}\right)$-embedded culture techniques. For 2dimensional (2D) low attachment culture, $60 \mathrm{~mm}$ non-treated culture dishes (Eppendorf, USA) were used. $10^{6}$ cells were collected and suspended onto each dish using three induction media mentioned above. For 3D hanging-drop culture, GravityPLUS ${ }^{\mathrm{TM}}$ 96-well plate hanging-drop culture system (PerkinElmer, USA) was used. Cells were suspended in induction media and seeded into hanging-drop wells at concentration $2 \times 10^{4}$ cells per $40 \mu \mathrm{L}$ per well. Another protocol was 3D hydrogel-embedded culture. Cell colonies obtained from hanging-drop culture were collected and embedded in hydrogel (Matrige ${ }^{\circledR}$ Matrix: growth factor reduced type) (Corning). In this regard, $100-150 \mu \mathrm{L}$ of hydrogel and induction medium mixture (1:1) was used for forming a dome-like structure onto each well of 24-well culture plate (Corning). Cell Recovery Solution ${ }^{\circledR}$ was used for gel digestion.

\section{IPC induction by genetic manipulation}

Overexpression of $P D X 1$ by lentiviral vector was used for genetic manipulating approach. Lentivirus carrying $P D X 1$ was produced from the packaging of $p W P T-P D X 1$ (Addgene plasmid \#12256; gift from Didier Trono) (http://n2t.net/addgene:12256; RRID: Addgene_12256) ${ }^{34}$, psPAX2 (Addgene plasmid \#12260; gift from Didier Trono) (http://n2t.net/addgene:12260; 
RRID: Addgene_12260), and pMD2.G (Addgene plasmid \#12259; gift from Didier Trono) (http://n2t.net/addgene:12259; RRID: Addgene_12259) in human embryonal kidney (HEK 293FT) cells. The supernatant containing lentiviral particles were collected at 48- and 72-hour post-packaging and filtered through $0.45 \mu \mathrm{m}$ filter. Viral particles were harvested using Plasmid Midiprep Plus Purification Kit (Gene Mark Bio, Taiwan) and then freshly concentrated by Amicon ${ }^{\circledR}$ Ultra Centrifugal Filter (Merck Millipore, USA).

For transfection protocol, cells at concentration of $5 \times 10^{4}$ cells/well were seeded onto 24well plates for 24 hours, then treated with $4 \mu \mathrm{g} / \mathrm{mL}$ polybrene infection/transfection reagent (Merck Millipore) for 30 minutes. Multiplicity of infection (MOI) at 20, 30, or 50 were used for each 24-hour-transfection course.

\section{Reverse transcription-quantitative polymerase chain reaction (RT-qPCR)}

RT-qPCR was used for mRNA analysis. The total RNA was collected using TRIzol-RNA isolation reagent (Thermo Fisher Scientific Corporation) and extracted by DirectZol-RNA isolation kit (ZymoResearch, USA) according to the manufacture's protocol. RNA was converted to complementary DNA (cDNA) using ImProm ${ }^{\mathrm{TM}}$ Reverse Transcription System (Promega, USA). The amplification of targeted genes was carried out by FastStart Essential DNA Green Master (Roche Diagnostics, Switzerland) using CFX96 ${ }^{\mathrm{TM}}$ Real-Time PCR Detection System (BioRad) with specific amplification primers. Glyceraldehyde 3-phosphate dehydrogenase, Gapdh, was used as the reference gene. Relative mRNA expression of target genes was normalized with reference gene and control group. The primer sequences were listed in Supplementary Table S1. 


\section{Functional analysis for IPCs}

Glucose-stimulated C-peptide secretion (GSCS) was used for functional analysis of IPCs. Two glucose concentrations were used, 5.5 and $22 \mathrm{mM}$. Krebs-Ringer bicarbonate HEPES $(\mathrm{KRBH})$ at $\mathrm{pH} 7.4$ was used as physiological buffer solution according to previous reports ${ }^{16,97,98}$. KRBH buffer solution contained $120 \mathrm{mM} \mathrm{NaCl}, 5 \mathrm{mM} \mathrm{KCl}, 2.5 \mathrm{mM} \mathrm{CaCl}_{2}, 1.1 \mathrm{mM} \mathrm{MgCl}, 25$ $\mathrm{mM} \mathrm{NaHCO}$, and $10 \mathrm{mM}$ HEPES. IPCs were gently collected and maintained with $\mathrm{KRBH}$ buffer solution at $37^{\circ} \mathrm{C}$ for 60 minutes as basal C-peptide secretion ( $0 \mathrm{mM}$ glucose $)$, then respectively incubated in $5.5 \mathrm{mM}(99 \mathrm{mg} / \mathrm{dL})$ and $22 \mathrm{mM}(396 \mathrm{mg} / \mathrm{dL})$ glucose (Sigma-Aldrich) for 60 minutes each. Buffer solution in each incubation period was collected for measuring Cpeptide concentration using canine C-peptide enzyme-linked immunosorbent assay (ELISA) kit (Merk Millipore) according to the manufacturing protocol. Secreted C-peptide levels were then normalized with total DNA (mg) and incubation time (minutes). Total DNA was measured by DNeasy Blood and Tissue Kit (Qiagen, CA) and Qubit fluorometer (Thermo Fisher Scientific).

\section{Statistical analysis}

The results were illustrated as whisker and box plot $(\mathrm{N}=4)$. Statistical analysis was determined using SPSS statistics 22 software (IBM Corporation, USA). Mann-Whitney $U$ test was used for comparing two independent samples, while Kruskal Wallis test and pairwise comparison were used for three or more group comparison. The significant difference was considered when $p$-value $<0.05$. 


\section{Data availability}

The datasets generated during and/or analyzed during the current study are available from the corresponding author on reasonable request.

\section{References}

1 BanfieldPetHospital. State of Pet Health® 2016 Report. 12-14 (2016).

2 Nerhagen, S. \& Mooney, C. Canine diabetes mellitus. Veterinary Ireland Journal 7, 241244 (2017).

3 WorldHealthOrganization. Global report on diabetes., (2016).

4 American Diabetes, A. 2. Classification and Diagnosis of Diabetes: Standards of Medical Care in Diabetes-2019. Diabetes Care 42, S13-S28, doi:10.2337/dc19-S002 (2019).

5 Handelsman, Y. et al. American Association of Clinical Endocrinologists and American College of Endocrinology - Clinical Practice Guidelines for Developing a Diabetes Mellitus Comprehensive Care Plan - 2015. Endocrine Practice 21, 1-87, doi:10.4158/ep15672.Glsuppl (2015).

6 Emamaullee, J. \& James Shapiro, A. in Principles of Regenerative Medicine (eds A Atala, R Lanza, JA Thomson, \& RM Nerem) Ch. 47, 794-811 (2008).

7 Kandaswamy, R. \& Sutherland, D. E. Pancreas versus islet transplantation in diabetes mellitus: How to allocate deceased donor pancreata? Transplant Proc 38, 365-367, doi:10.1016/j.transproceed.2006.01.005 (2006).

8 Serup, P., Madsen, O. D. \& Mandrup-Poulsen, T. Islet and stem cell transplantation for treating diabetes. BMJ 322, 29-32, doi:10.1136/bmj.322.7277.29 (2001). 
9 Brennan, D. C. et al. Long-Term Follow-Up of the Edmonton Protocol of Islet Transplantation in the United States. Am J Transplant 16, 509-517, doi:10.1111/ajt.13458 (2016).

10 Bose, B., Katikireddy, K. \& Shenoy P, S. Regenerative Medicine for Diabetes: Differentiation of Human Pluripotent Stem Cells into Functional $\beta$-Cells In Vitro and Their Proposed Journey to Clinical Translation. Vitamis and Hormones 95, 223-248 (2014).

11 Vanikar, A. V., Trivedi, H. L. \& Thakkar, U. G. Stem cell therapy emerging as the key player in treating type 1 diabetes mellitus. Cytotherapy 18, 1077-1086, doi:10.1016/j.jcyt.2016.06.006 (2016).

12 Zhou, Q., Brown, J., Kanarek, A., Rajagopal, J. \& Melton, D. A. In vivo reprogramming of adult pancreatic exocrine cells to beta-cells. Nature 455, 627-632, doi:10.1038/nature07314 (2008).

13 Brevini, T. A. et al. Epigenetic conversion of adult dog skin fibroblasts into insulinsecreting cells. Vet J 211, 52-56, doi:10.1016/j.tvj1.2016.02.014 (2016).

14 Takemitsu, H. et al. Mechanism of insulin production in canine bone marrow derived mesenchymal stem cells. Gen Comp Endocrinol 189, 1-6, doi:10.1016/j.ygcen.2013.04.009 (2013).

15 Kuncorojakti, S., Srisuwatanasagul, S., Kradangnga, K. \& Sawangmake, C. InsulinProducing Cell Transplantation Platform for Veterinary Practice. Front Vet Sci 7, 4, doi:10.3389/fvets.2020.00004 (2020).

16 Sawangmake, C., Nowwarote, N., Pavasant, P., Chansiripornchai, P. \& Osathanon, T. A feasibility study of an in vitro differentiation potential toward insulin-producing cells by 
dental tissue-derived mesenchymal stem cells. Biochem Biophys Res Commun 452, 581587, doi:10.1016/j.bbrc.2014.08.121 (2014).

17 Domouky, A. M., Hegab, A. S., Al-Shahat, A. \& Raafat, N. Mesenchymal stem cells and differentiated insulin producing cells are new horizons for pancreatic regeneration in type I diabetes mellitus. Int J Biochem Cell Biol 87, 77-85, doi:10.1016/j.biocel.2017.03.018 (2017).

18 Gabr, M. et al. Insulin-producing Cells from Adult Human Bone Marrow Mesenchymal Stromal Cells Could Control Chemically Induced Diabetes in Dogs: A Preliminary Study. Cell transplantation, 1-11, doi:10.1177/09636897|8759913 (2018).

19 James Shapiro, A. et al. International Trial of the Edmonton Protocol for Islet Transplantation. The new england journal of medicine 355, 1318-1330 (2006).

20 Tekin, Z. et al. Outcomes of Pancreatic Islet Allotransplantation Using the Edmonton Protocol at the University of Chicago. Transplantation Direct 2, e105, doi:10.1097/TXD.000000000000609 (2016).

21 Betts, D. H. \& Tobias, I. C. Canine Pluripotent Stem Cells: Are They Ready for Clinical Applications? Front Vet Sci 2, 41, doi:10.3389/fvets.2015.00041 (2015).

22 Black, L. \& Zorina, T. Cell-based immunomodulatory therapy approaches for type 1 diabetes mellitus. Drug Discov Today 25, 380-391, doi:10.1016/j.drudis.2019.11.016 (2020).

23 Linder, U., Kramer, J., Rohwedel, J. \& Schlenke, P. Mesenchymal Stem or Stromal Cells: Toward a Better Understanding of Their Biology? Transfus Med Hemother 37, 7583 (2010). 
24 Sen, S. Adult Stem Cells: Beyond Regenerative Tool, More as a Bio-Marker in Obesity and Diabetes. Diabetes Metab J 43, 744-751, doi:10.4093/dmj.2019.0175 (2019).

25 Duan, W. \& Lopez, M. J. Canine Adult Adipose Tissue-Derived Multipotent Stromal Cell Isolation and Characterization. Methods Mol Biol 1773, 189-202, doi:10.1007/9781-4939-7799-4_16(2018).

26 Mohamed-Ahmed, S. et al. Adipose-derived and bone marrow mesenchymal stem cells: a donor-matched comparison. Stem Cell Res Ther 9, 168, doi:10.1186/s13287-018-09141 (2018).

27 Nantavisai, S. et al. Simvastatin enhances proliferation and pluripotent gene expression by canine bone marrow-derived mesenchymal stem cells (cBM-MSCs) in vitro. Heliyon 5, e02663, doi:10.1016/j.heliyon.2019.e02663 (2019).

28 Sawangmake, C., Nantavisai, S., Osathanon, T. \& Pavasant, P. Osteogenic differentiation potential of canine bone marrowderived mesenchymal stem cells under different $\square$ glycerophosphate concentrations in vitro. Thai J Vet Med 46, 617-625 (2016).

29 Kirkham, G. \& Cartmell, S. in Tissue Engineering Vol. 3 (eds N Ashammakhi, R Reis, \& E Chiellini) (2007).

30 Teshima, T. et al. Comparison of Properties of Stem Cells Isolated from Adipose Tissue and Lipomas in Dogs. Stem Cells Int 2019, 1609876, doi:10.1155/2019/1609876 (2019).

31 Russell, K. A. et al. Characterization and Immunomodulatory Effects of Canine Adipose Tissue- and Bone Marrow-Derived Mesenchymal Stromal Cells. PLoS One 11, e0167442, doi:10.1371/journal.pone.0167442 (2016). 
32 Chandra, V., G, S., Phadnis, S., Nair, P. D. \& Bhonde, R. R. Generation of pancreatic hormone-expressing islet-like cell aggregates from murine adipose tissue-derived stem cells. Stem Cells 27, 1941-1953, doi:10.1002/stem.117 (2009).

33 Rahmati, S., Alijani, N. \& Kadivar, M. In vitro generation of glucose-responsive insulin producing cells using lentiviral based pdx-1 gene transduction of mouse (C57BL/6) mesenchymal stem cells. Biochem Biophys Res Commun 437, 413-419, doi:10.1016/j.bbrc.2013.06.092 (2013).

34 Ritz-Laser, B. et al. Ectopic expression of the beta-cell specific transcription factor Pdx1 inhibits glucagon gene transcription. Diabetologia 46, 810-821, doi:10.1007/s00125-0031115-7 (2003).

35 Sawangmake, C., Rodprasert, W., Osathanon, T. \& Pavasant, P. Integrative protocols for an in vitro generation of pancreatic progenitors from human dental pulp stem cells. Biochem Biophys Res Commun 530, 222-229, doi:10.1016/j.bbrc.2020.06.145 (2020).

36 Yamada, T. et al. Reprogramming Mouse Cells With a Pancreatic Duct Phenotype to Insulin-Producing beta-Like Cells. Endocrinology 156, 2029-2038, doi:10.1210/en.20141987 (2015).

37 Holde, K. \& Zlatanova, J. in The Evolution of Molecular Biology: The Search for the Secrets of Life (eds K Gomez \& P Gonzalez) Ch. 13, 135-147 (Sara Tenney, 2018).

38 Rosenberg, L. E. \& Rosenberg, D. D. in Human Genes and Genomes: Science, Health, Society Ch. 4, 27-50 (2012).

39 Sakhneny, L., Khalifa-Malka, L. \& Landsman, L. Pancreas organogenesis: Approaches to elucidate the role of epithelial-mesenchymal interactions. Semin Cell Dev Biol, doi:10.1016/j.semcdb.2018.08.012 (2018). 
40 Wu, J. \& Izpisua Belmonte, J. C. Stem Cells: A Renaissance in Human Biology Research. Cell 165, 1572-1585, doi:10.1016/j.cell.2016.05.043 (2016).

41 Xin, T., Greco, V. \& Myung, P. Hardwiring Stem Cell Communication through Tissue Structure. Cell 164, 1212-1225, doi:10.1016/j.cell.2016.02.041 (2016).

42 Cozzitorto, C. \& Spagnoli, F. M. Pancreas organogenesis: The interplay between surrounding microenvironment(s) and epithelium-intrinsic factors. Curr Top Dev Biol 132, 221-256, doi:10.1016/bs.ctdb.2018.12.005 (2019).

43 Jeon, K. et al. Differentiation and transplantation of functional pancreatic beta cells generated from induced pluripotent stem cells derived from a type 1 diabetes mouse model. Stem Cells Dev 21, 2642-2655, doi:10.1089/scd.2011.0665 (2012).

44 Lumelsky, N. et al. Differentiation of embryonic stem cells to insulin-secreting structures similar to pancreatic islets. Science 292, 1389-1394, doi:10.1126/science.1058866 (2001).

45 Memon, B. \& Abdelalim, E. M. Stem Cell Therapy for Diabetes: Beta Cells versus Pancreatic Progenitors. Cells 9, doi:10.3390/cells9020283 (2020).

46 Pan, G., Mu, Y., Hou, L. \& Liu, J. Examining the therapeutic potential of various stem cell sources for differentiation into insulin-producing cells to treat diabetes. Ann Endocrinol (Paris) 80, 47-53, doi:10.1016/j.ando.2018.06.1084 (2019).

47 Zhou, Q. \& Melton, D. A. Pancreas regeneration. Nature 557, 351-358, doi:10.1038/s41586-018-0088-0 (2018).

48 Gonez, L. J. \& Knight, K. R. Cell therapy for diabetes: stem cells, progenitors or betacell replication? Mol Cell Endocrinol 323, 55-61, doi:10.1016/j.mce.2009.12.014 (2010). 
49 Lin, C., Xin, Z., Dai, J. \& Lue, T. Commonly Used Mesenchymal Stem Cell Markers and Tracking Labels: Limitations and Challenges. Histol Histopathol 28, 1109-1116 (2013).

50 Mohamed, A., Saad, M., Abdeen, S. \& Marei, M. Generation of Insulin Producing Cells using Mesenchymal Stem Cells Derived from Bone Marrow of New-Zealand White Rabbits. Canadian Journal of Clinical Nutrition 1, 47-66, doi:10.14206/canad.j.clin.nutr.2013.01.06 (2013).

51 Amer, M. G., Embaby, A. S., Karam, R. A. \& Amer, M. G. Role of adipose tissue derived stem cells differentiated into insulin producing cells in the treatment of type I diabetes mellitus. Gene 654, 87-94, doi:10.1016/j.gene.2018.02.008 (2018).

52 Gabr, M. M. et al. From Human Mesenchymal Stem Cells to Insulin-Producing Cells: Comparison between Bone Marrow- and Adipose Tissue-Derived Cells. Biomed Res Int 2017, 3854232, doi:10.1155/2017/3854232 (2017).

53 Millman, J. R. et al. Generation of stem cell-derived beta-cells from patients with type 1 diabetes. Nat Commun 7, 11463, doi:10.1038/ncomms11463 (2016).

54 Mochida, T. et al. Insulin-Deficient Diabetic Condition Upregulates the Insulin-Secreting Capacity of Human Induced Pluripotent Stem Cell-Derived Pancreatic Endocrine Progenitor Cells After Implantation in Mice. Diabetes 69, 634-646, doi:10.2337/db190728 (2020). Petersen, M. B. K. et al. Single-Cell Gene Expression Analysis of a Human ESC Model of Pancreatic Endocrine Development Reveals Different Paths to beta-Cell Differentiation. Stem Cell Reports 9, 1246-1261, doi:10.1016/j.stemcr.2017.08.009 (2017). 
56 Wang, X. et al. Genome-wide analysis of PDX1 target genes in human pancreatic progenitors. Mol Metab 9, 57-68, doi:10.1016/j.molmet.2018.01.011 (2018).

57 Sawangmake, C. in Stem Cells and Tissue Engineering of Oral and Maxillofacial Structures (eds T Osathanon et al.) Ch. 13, 249-278 (2015).

58 Agulnick, A. D. et al. Insulin-Producing Endocrine Cells Differentiated In Vitro From Human Embryonic Stem Cells Function in Macroencapsulation Devices In Vivo. Stem Cells Transl Med 4, 1214-1222, doi:10.5966/sctm.2015-0079 (2015).

59 Govindasamy, V. et al. Differentiation of dental pulp stem cells into islet-like aggregates. J Dent Res 90, 646-652, doi:10.1177/0022034510396879 (2011).

$60 \mathrm{Li}$, F. et al. Combined activin $\mathrm{A} / \mathrm{LiCl} / \mathrm{Noggin}$ treatment improves production of mouse embryonic stem cell-derived definitive endoderm cells. J Cell Biochem 112, 1022-1034, doi:10.1002/jcb.22962 (2011).

61 McLean, A. B. et al. Activin a efficiently specifies definitive endoderm from human embryonic stem cells only when phosphatidylinositol 3-kinase signaling is suppressed. Stem Cells 25, 29-38, doi:10.1634/stemcells.2006-0219 (2007).

62 Xu, X., Browning, V. L. \& Odorico, J. S. Activin, BMP and FGF pathways cooperate to promote endoderm and pancreatic lineage cell differentiation from human embryonic stem cells. Mech Dev 128, 412-427, doi:10.1016/j.mod.2011.08.001 (2011).

63 Grimm, D. et al. Tissue Engineering Under Microgravity Conditions-Use of Stem Cells and Specialized Cells. Stem Cells Dev 27, 787-804, doi:10.1089/scd.2017.0242 (2018).

64 Ikemoto, T. et al. In vitro and in vivo effects of insulin-producing cells generated by xeno-antigen free 3D culture with RCP piece. Sci Rep 9, 10759, doi:10.1038/s41598019-47257-7 (2019). 
65 Tran, R., Moraes, C. \& Hoesli, C. A. Controlled clustering enhances PDX1 and NKX6.1 expression in pancreatic endoderm cells derived from pluripotent stem cells. Sci Rep 10, 1190, doi:10.1038/s41598-020-57787-0 (2020).

66 Behringer, R., Gertsenstein, M., Nagy, K. V. \& Nagy, A. Differentiating Mouse Embryonic Stem Cells into Embryoid Bodies by Hanging-Drop Cultures. Cold Spring Harb Protoc 2016, doi:10.1101/pdb.prot092429 (2016).

67 Foty, R. A simple hanging drop cell culture protocol for generation of 3D spheroids. $J$ Vis Exp, doi:10.3791/2720 (2011).

68 Shri, M., Agrawal, H., Rani, P., Singh, D. \& Onteru, S. K. Hanging Drop, A Best ThreeDimensional (3D) Culture Method for Primary Buffalo and Sheep Hepatocytes. Sci Rep 7, 1203, doi:10.1038/s41598-017-01355-6 (2017).

69 Wang, S. et al. Application of Hanging Drop Technique for Kidney Tissue Culture. Kidney Blood Press Res 42, 220-231, doi:10.1159/000476018 (2017).

70 Blondel, D. \& Lutolf, M. P. Bioinspired Hydrogels for 3D Organoid Culture. Chimia (Aarau) 73, 81-85, doi:10.2533/chimia.2019.81 (2019).

71 Broguiere, N. et al. Growth of Epithelial Organoids in a Defined Hydrogel. Adv Mater 30, e1801621, doi:10.1002/adma.201801621 (2018).

72 Capeling, M. M. et al. Nonadhesive Alginate Hydrogels Support Growth of Pluripotent Stem Cell-Derived Intestinal Organoids. Stem Cell Reports 12, 381-394, doi:10.1016/j.stemcr.2018.12.001 (2019).

73 Cruz-Acuna, R. et al. Synthetic hydrogels for human intestinal organoid generation and colonic wound repair. Nat Cell Biol 19, 1326-1335, doi:10.1038/ncb3632 (2017). 
74 Giobbe, G. G. et al. Extracellular matrix hydrogel derived from decellularized tissues enables endodermal organoid culture. Nat Commun 10, 5658, doi:10.1038/s41467-01913605-4 (2019).

75 Hebrok, M. Generating beta cells from stem cells-the story so far. Cold Spring Harb Perspect Med 2, a007674, doi:10.1101/cshperspect.a007674 (2012).

76 Boroujeni, Z. N. \& Aleyasin, A. Insulin producing cells established using non-integrated lentiviral vector harboring PDX1 gene. World J Stem Cells 5, 217-228, doi:10.4252/wjsc.v5.i4.217 (2013).

77 Van Pham, P. et al. Improved differentiation of umbilical cord blood-derived mesenchymal stem cells into insulin-producing cells by PDX-1 mRNA transfection. Differentiation 87, 200-208, doi:10.1016/j.diff.2014.08.001 (2014).

78 Karaoz, E. et al. Adipose tissue-derived mesenchymal stromal cells efficiently differentiate into insulin-producing cells in pancreatic islet microenvironment both in vitro and in vivo. Cytotherapy 15, 557-570, doi:10.1016/j.jcyt.2013.01.005 (2013).

79 Mohamad Buang, M. L., Seng, H. K., Chung, L. H., Saim, A. B. \& Idrus, R. B. In vitro generation of functional insulin-producing cells from lipoaspirated human adipose tissuederived stem cells. Arch Med Res 43, 83-88, doi:10.1016/j.arcmed.2012.01.012 (2012).

80 Timper, K. et al. Human adipose tissue-derived mesenchymal stem cells differentiate into insulin, somatostatin, and glucagon expressing cells. Biochem Biophys Res Commun 341, 1135-1140, doi:10.1016/j.bbrc.2006.01.072 (2006).

81 Marappagounder, D., Somasundaram, I., Dorairaj, S. \& Sankaran, R. J. Differentiation of mesenchymal stem cells derived from human bone marrow and subcutaneous adipose 
tissue into pancreatic islet-like clusters in vitro. Cell Mol Biol Lett 18, 75-88, doi:10.2478/s11658-012-0040-5 (2013).

82 Bar, Y. \& Efrat, S. The NOTCH pathway in beta-cell growth and differentiation. Vitam Horm 95, 391-405, doi:10.1016/B978-0-12-800174-5.00015-6 (2014).

83 Billiard, F. et al. Delta-like Ligand-4-Notch Signaling Inhibition Regulates Pancreatic Islet Function and Insulin Secretion. Cell Rep 22, 895-904, doi:10.1016/j.celrep.2017.12.076 (2018).

84 Larsen, H. L. \& Grapin-Botton, A. The molecular and morphogenetic basis of pancreas organogenesis. Semin Cell Dev Biol 66, 51-68, doi:10.1016/j.semcdb.2017.01.005 (2017).

85 Li, X. Y., Zhai, W. J. \& Teng, C. B. Notch Signaling in Pancreatic Development. Int J Mol Sci 17, doi:10.3390/ijms17010048 (2015).

$86 \mathrm{Qu}, \mathrm{X}$. et al. Notch-mediated post-translational control of Ngn3 protein stability regulates pancreatic patterning and cell fate commitment. Dev Biol 376, 1-12, doi:10.1016/j.ydbio.2013.01.021 (2013).

87 Jensen, J. Gene regulatory factors in pancreatic development. Dev Dyn 229, 176-200, doi:10.1002/dvdy.10460 (2004).

88 Stanger, B. Z. \& Hebrok, M. Control of cell identity in pancreas development and regeneration. Gastroenterology 144, 1170-1179, doi:10.1053/j.gastro.2013.01.074 (2013).

89 Wilson, M. E., Scheel, D. \& German, M. S. Gene expression cascades in pancreatic development. Mech Dev 120, 65-80 (2003). 
90 Gradwohl, G., Dierich, A., LeMeur, M. \& Guillemot, F. Neurogenin3 is required for the development of the four endocrine cell lineages of the pancreas. PNAS 97, 1607-1611 (2000).

91 Gu, G., Brown, J. R. \& Melton, D. A. Direct lineage tracing reveals the ontogeny of pancreatic cell fates during mouse embryogenesis. Mech Dev 120, 35-43 (2003).

92 Bar, Y. et al. Redifferentiation of expanded human pancreatic beta-cell-derived cells by inhibition of the NOTCH pathway. J Biol Chem 287, 17269-17280, doi:10.1074/jbc.M111.319152 (2012).

93 Darville, M. I. \& Eizirik, D. L. Notch signaling: a mediator of beta-cell de-differentiation in diabetes? Biochem Biophys Res Commun 339, 1063-1068, doi:10.1016/j.bbrc.2005.11.111 (2006).

94 Jafarian, A. et al. The Generation of Insulin Producing Cells from Human Mesenchymal Stem Cells by MiR-375 and Anti-MiR-9. PLoS One 10, e0128650, doi:10.1371/journal.pone.0128650 (2015).

95 Bertolo, A., Steffen, F., Malonzo-Marty, C. \& Stoyanov, J. Canine Mesenchymal Stem Cell Potential and the Importance of Dog Breed: Implication for Cell-Based Therapies. Cell Transplant 24, 1969-1980, doi:10.3727/096368914X685294 (2015).

96 Saeedi, P. et al. Global and regional diabetes prevalence estimates for 2019 and projections for 2030 and 2045: Results from the International Diabetes Federation Diabetes Atlas, 9(th) edition. Diabetes Res Clin Pract 157, 107843, doi:10.1016/j.diabres.2019.107843 (2019). 
97 Gopurappilly, R., Bhat, V. \& Bhonde, R. Pancreatic tissue resident mesenchymal stromal cell (MSC)-like cells as a source of in vitro islet neogenesis. J Cell Biochem 114, 22402247, doi:10.1002/jcb.24572 (2013).

98 Luppi, P. \& Drain, P. Autocrine C-peptide mechanism underlying INS1 beta cell adaptation to oxidative stress. Diabetes Metab Res Rev 30, 599-609, doi:10.1002/dmrr.2528 (2014).

\section{Acknowledgements}

WR and SN were supported by the $100^{\text {th }}$ Anniversary Chulalongkorn University Fund for Doctoral Scholarship, the $90^{\text {th }}$ Anniversary Chulalongkorn University Fund, and Veterinary Clinical Stem Cell and Bioengineering Research Unit, Ratchadaphiseksomphot Endowment Fund, Chulalongkorn University. TO and PP were supported by Chulalongkorn Academic Advancement into Its $2^{\text {nd }}$ Century Project. CS was supported by Chulalongkorn Academic Advancement into Its $2^{\text {nd }}$ Century Project, Veterinary Clinical Stem Cell and Bioengineering Research Unit, Ratchadaphiseksomphot Endowment Fund, Chulalongkorn University, and Government Research Fund. The authors thank Professor Kaywalee Chatdarong (D.V.M., Ph.D.), Department of Obstetrics, Gynaecology and Reproduction, Faculty of Veterinary Science, Chulalongkorn University, for providing support on qPCR analysis; Ms Daneeya Chaikiawkeaw (B.Sc., M.Sc.), Center of Excellence for Regenerative Dentistry, Faculty of Dentistry, Chulalongkorn University, for helping on microplate analysis; Mr. Noppadol Sa-ardiam (B.Sc.), Immunology Research Center, Faculty of Dentistry, Chulalongkorn University, for supporting on flow cytometry analysis; and the Veterinary Stem Cell and Bioengineering 
Innovation Center (VSCBIC) (http://www.cuvscbic.com/), Faculty of Veterinary Science, Chulalongkorn University, for providing research facility support.

\section{Author contributions}

WR performed most of experiments, collected data, analyzed and interpreted data, and wrote manuscript. SN and KP provided study material and collected data. TO and PP supervised the project. CS conceived and designed the experiments, analyzed and interpreted data, wrote and approved the final manuscript.

\section{Competing interests}

The authors declare no competing interests.

\section{Figure Legends}

Figure 1 cBM-MSC and CAD-MSC characterization. Morphological appearances of cBMMSCs (A and B) and cAD-MSCs (C and D) were observed under phase-contrast microscope with magnification of 40X and 200X. mRNA expression regarding stemness and proliferation markers (E and F) were determined by RT-qPCR. mRNA expression was normalized with reference gene. The MSC-related surface markers were analyzed using flow cytometry (G and H). Osteogenic differentiation potential at day 14 post-induction was determined by Alizarin Red S and Von Kossa staining (I and J). Osteogenic mRNA marker expression was analyzed by RTqPCR (K and L). mRNA expression was normalized with reference gene and undifferentiated control. Bars indicated significant difference $(*, p$-value $<0.05)$. 
Figure 2 Generation of cBM-MSC-derived IPCs by microenvironmental manipulation.

Diagrams of three culture techniques used for the generation of cBM-MSC-derived IPCs were showed: I) low attachment (A), II) hanging-drop (B), and III) hydrogel-embedded (C) culture techniques. Morphological appearances of cells undergone each of induction technique were observed under phase-contrast microscope with magnification of $100 \mathrm{X}$ and 200X (D). mRNA markers relating to pancreatic endoderm $(\mathrm{E})$, pancreatic beta-cell $(\mathrm{F})$, and pancreatic-relating markers $(\mathrm{G})$ were analyzed by RT-qPCR. mRNA expression was normalized with reference gene and undifferentiated control. Functional testing by glucose-stimulated C-peptide secretion (GSCS) was illustrated (H). Bars indicated significant difference $(*, p$-value $<0.05 ; * *, p<$ $0.01)$.

Figure 3 Generation of cBM-MSC-derived IPCs by genetic manipulation. Diagram of the PDX1 transfection for the generation of cBM-MSC-derived IPCs was showed (A). Morphological appearances of cells undergone each of transfection condition were observed under phase-contrast microscope with magnification of 40X, 100X and 200X (B). mRNA markers relating to pancreatic endoderm (C), pancreatic beta-cell (D), and pancreatic-relating markers (E) were analyzed by RT-qPCR. mRNA expression was normalized with reference gene and undifferentiated control. Bars indicated significant difference $(*, p$-value $<0.05 ; * *, p<$ $0.01 ; * * *, p<0.001)$.

Figure 4 Generation of cBM-MSC-derived IPCs by integrating genetic and microenvironmental manipulation. Diagram of culture technique used for the generation of cBM-MSC-derived IPCs was showed (A). Morphological appearances of cells undergone 
induction technique were observed under phase-contrast microscope with magnification of $40 \mathrm{X}$ and 200X (B). mRNA markers relating to pancreatic endoderm (C), pancreatic beta-cell (D), and pancreatic-relating markers (E) were analyzed by RT-qPCR. mRNA expression was normalized with reference gene and undifferentiated control. Functional testing by glucose-stimulated Cpeptide secretion (GSCS) was illustrated (F). Bars indicated significant difference $(*, p$-value < $0.05)$.

Figure 5 Generation of cAD-MSC-derived IPCs by microenvironmental manipulation. Diagram of culture technique used for the generation of cAD-MSC-derived IPCs was showed (A). Morphological appearances of cells undergone induction technique were observed under phase-contrast microscope with magnification of 40X and 200X (B). Total colony number (C) and colony size proportion (D) were evaluated. mRNA markers relating to pancreatic beta-cell (E), and pancreatic-relating markers $(\mathrm{F})$ were analyzed by RT-qPCR. mRNA expression was normalized with reference gene and undifferentiated control. Functional testing by glucosestimulated C-peptide secretion (GSCS) was illustrated (G). Bars indicated significant difference $(*, p$-value $<0.05)$.

\section{Figure 6 Generation of cAD-MSC-derived IPCs with Notch signaling manipulation.}

Diagrams of Notch signaling manipulation used for the generation of cAD-MSC-derived IPCs were showed (A-C). Morphological appearances of cells undergone each of induction technique were observed under phase-contrast microscope with magnification of 40X and 200X (D). Total colony number $(\mathrm{E})$ and colony size proportion $(\mathrm{F})$ were evaluated. 
Figure 7 Generation of cAD-MSC-derived IPCs with Notch signaling manipulation. mRNA markers relating to pancreatic endoderm (A), pancreatic beta-cell (B), pancreatic-relating markers (C), and Notch target genes (D) were analyzed by RT-qPCR. mRNA expression was normalized with reference gene and undifferentiated control. Functional testing by glucosestimulated C-peptide secretion (GSCS) was illustrated (E). Bars indicated significant difference $(*, p$-value $<0.05 ; * *, p<0.01 ; * * *, p<0.001)$. 


\section{Figures}

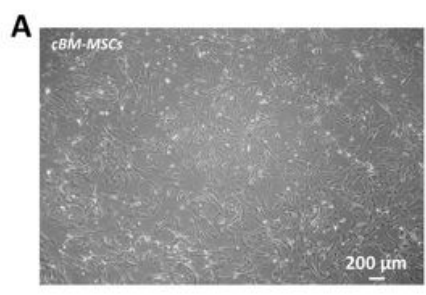

E

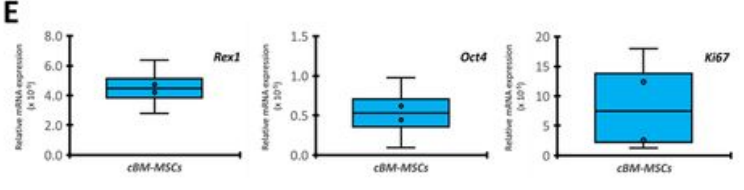

G
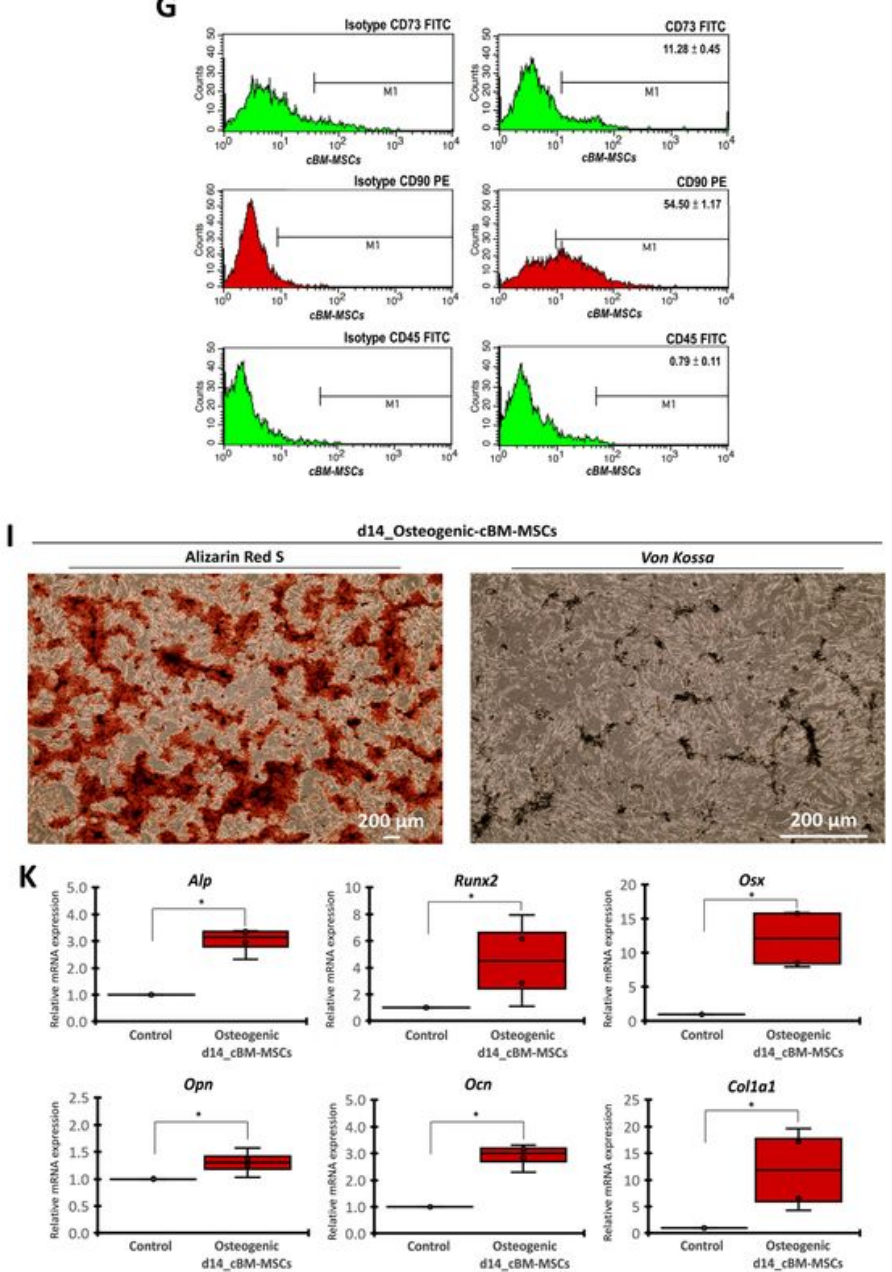
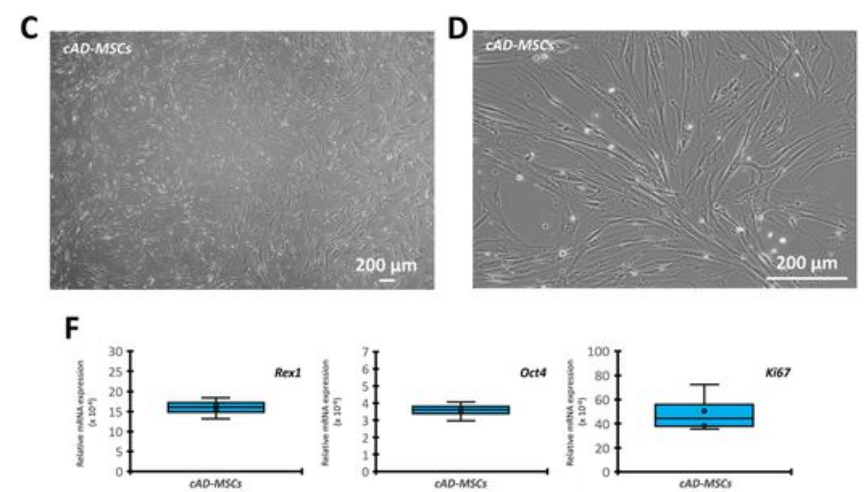

H
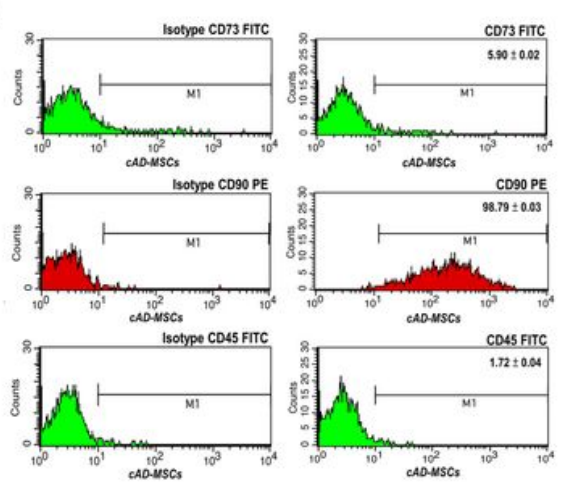

J
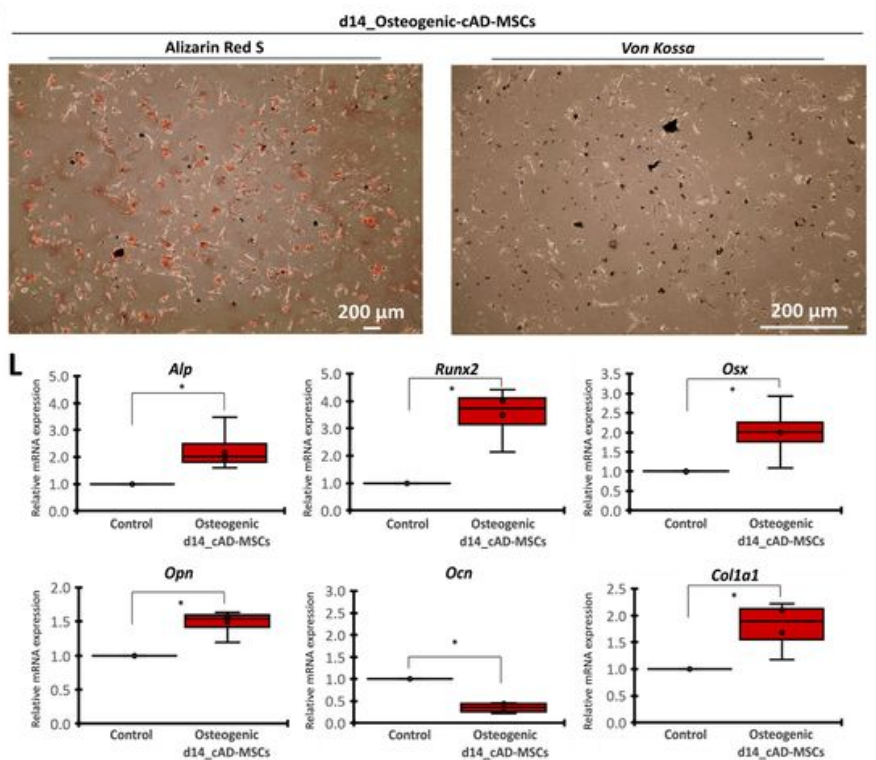

\section{Figure 1}

cBM-MSC and CAD-MSC characterization. Morphological appearances of cBM-MSCs (A and B) and CADMSCs ( $C$ and D) were observed under phase-contrast microscope with magnification of 40X and 200X. mRNA expression regarding stemness and proliferation markers ( $E$ and F) were determined by RT-qPCR. mRNA expression was normalized with reference gene. The MSC-related surface markers were analyzed 
using flow cytometry ( $\mathrm{G}$ and $\mathrm{H})$. Osteogenic differentiation potential at day 14 post-induction was determined by Alizarin Red $\mathrm{S}$ and Von Kossa staining (I and $\mathrm{J}$ ). Osteogenic mRNA marker expression was analyzed by RT-qPCR ( $\mathrm{K}$ and $\mathrm{L}$ ). mRNA expression was normalized with reference gene and undifferentiated control. Bars indicated significant difference $\left({ }^{*}, p\right.$-value $\left.<0.05\right)$.

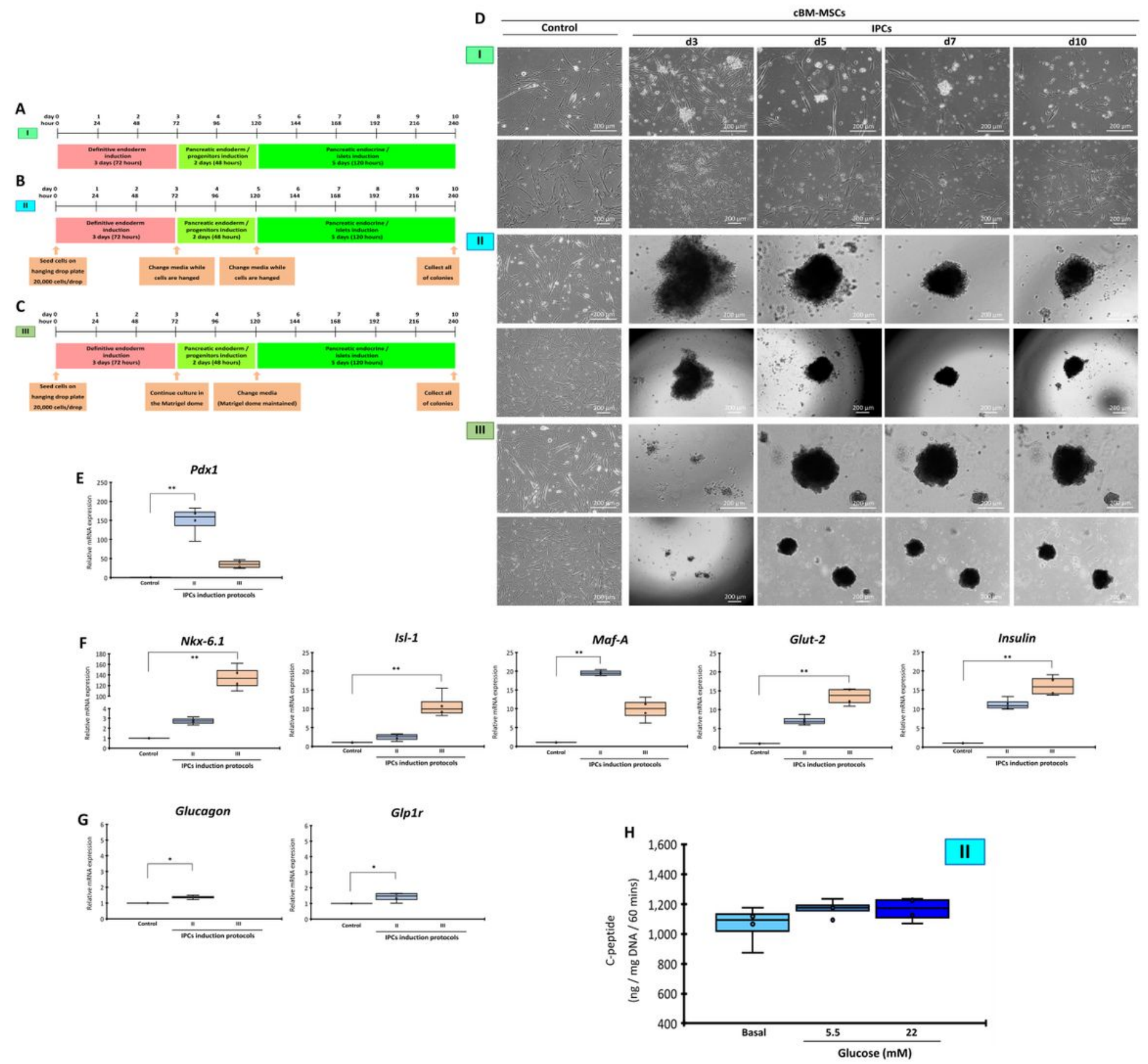

Figure 2

Generation of cBM-MSC-derived IPCs by microenvironmental manipulation. Diagrams of three culture techniques used for the generation of cBM-MSC-derived IPCs were showed: I) low attachment (A), II) 
hanging-drop (B), and III) hydrogel-embedded (C) culture techniques. Morphological appearances of cells undergone each of induction technique were observed under phase-contrast microscope with magnification of 100X and 200X (D). mRNA markers relating to pancreatic endoderm (E), pancreatic betacell (F), and pancreatic-relating markers (G) were analyzed by RT-qPCR. mRNA expression was normalized with reference gene and undifferentiated control. Functional testing by glucose-stimulated Cpeptide secretion (GSCS) was illustrated (H). Bars indicated significant difference $(*, p$-value $<0.05 ; \star \star, p<$ $0.01)$.

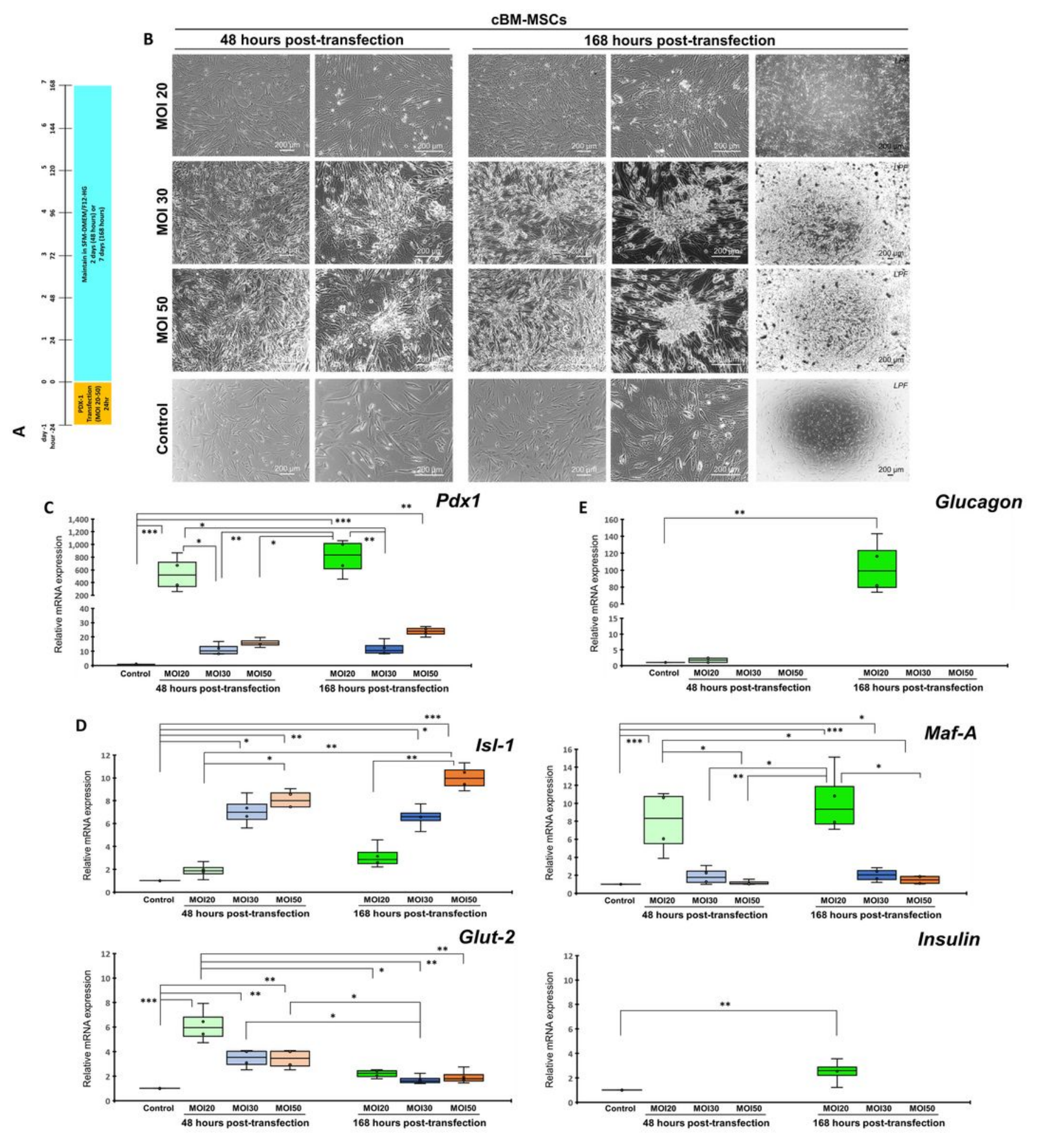

Figure 3 
Generation of cBM-MSC-derived IPCs by genetic manipulation. Diagram of the PDX1 transfection for the generation of cBM-MSC-derived IPCs was showed (A). Morphological appearances of cells undergone each of transfection condition were observed under phase-contrast microscope with magnification of 40X, 100X and 200X (B). mRNA markers relating to pancreatic endoderm (C), pancreatic beta-cell (D), and pancreatic-relating markers $(\mathrm{E})$ were analyzed by RT-qPCR. mRNA expression was normalized with reference gene and undifferentiated control. Bars indicated significant difference $(*, p$-value $<0.05 ; * \star, p<$ $0.01 ; * \star \star, p<0.001)$.

A

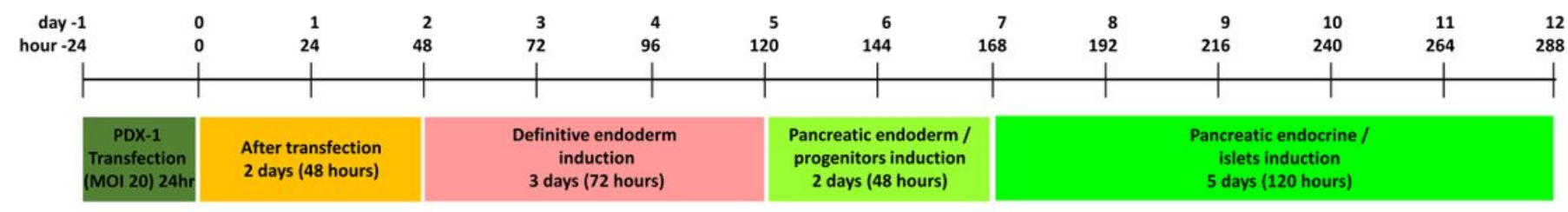

B

cBM-MSCs

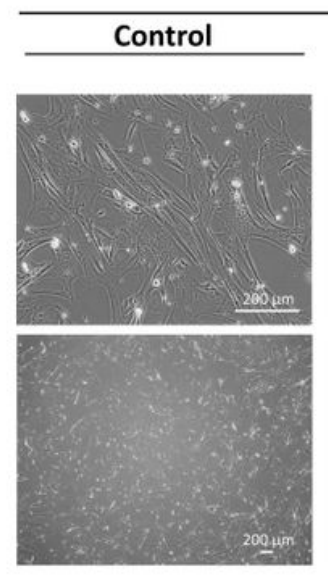

C

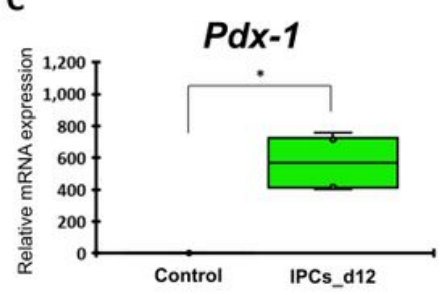

。

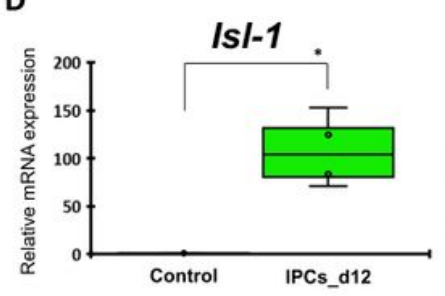

E

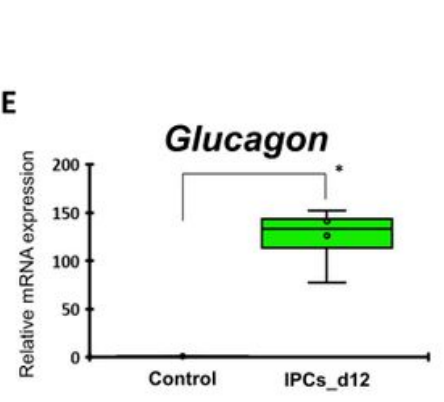

IPCS

d7
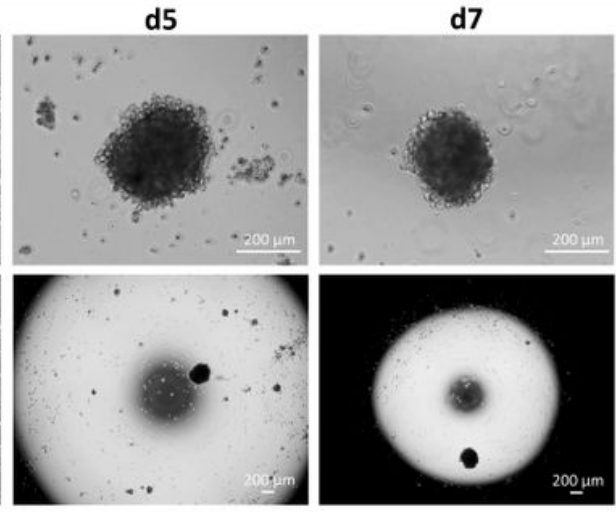

d9

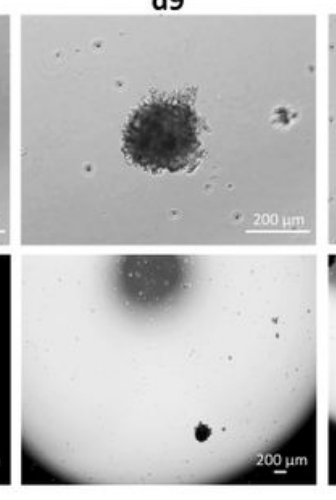

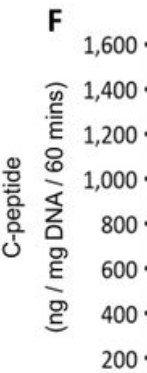
d12
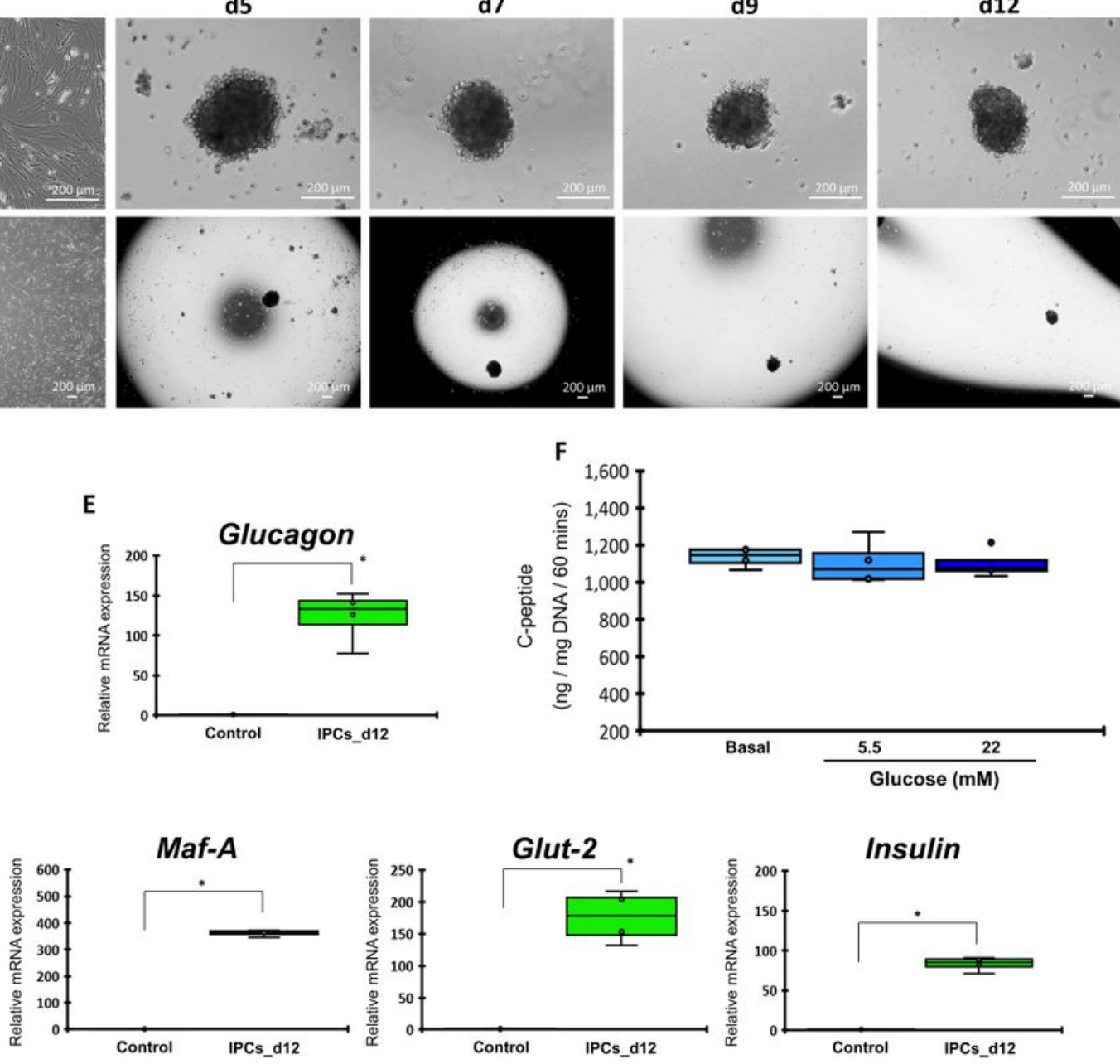
Generation of cBM-MSC-derived IPCs by integrating genetic and microenvironmental manipulation. Diagram of culture technique used for the generation of cBM-MSC-derived IPCs was showed (A). Morphological appearances of cells undergone induction technique were observed under phase-contrast microscope with magnification of 40X and 200X (B). mRNA markers relating to pancreatic endoderm (C), pancreatic beta-cell (D), and pancreatic-relating markers (E) were analyzed by RT-qPCR. mRNA expression was normalized with reference gene and undifferentiated control. Functional testing by glucosestimulated C-peptide secretion (GSCS) was illustrated (F). Bars indicated significant difference ( ${ }^{\star}, \mathrm{p}$-value $<0.05)$.

A

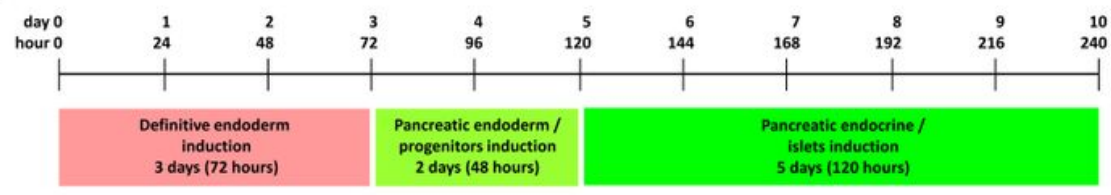

B

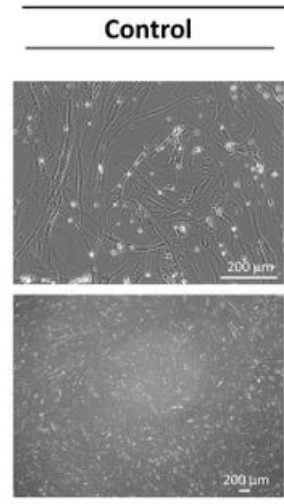

E

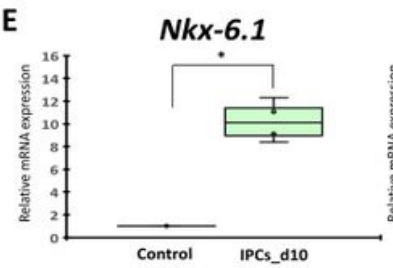

F

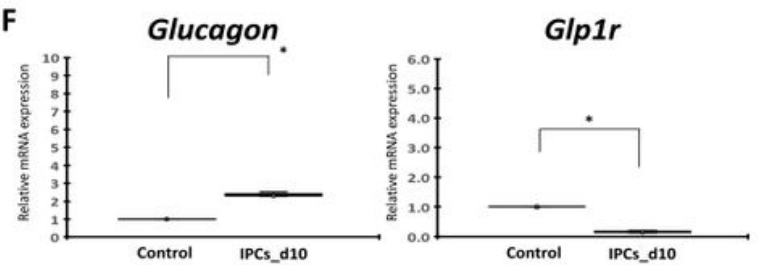

$|s|-1$
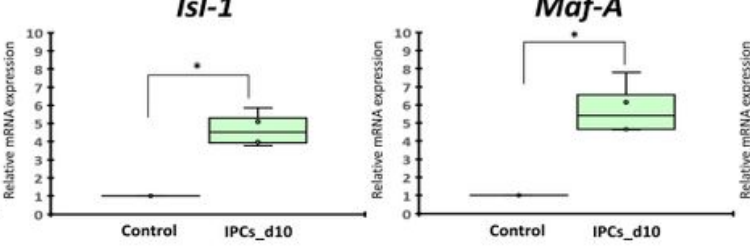

Control IPCs_d10
cAD-MSCs
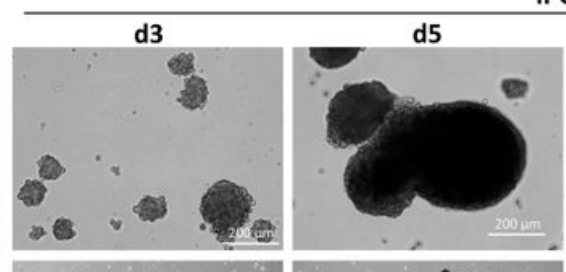

PCs
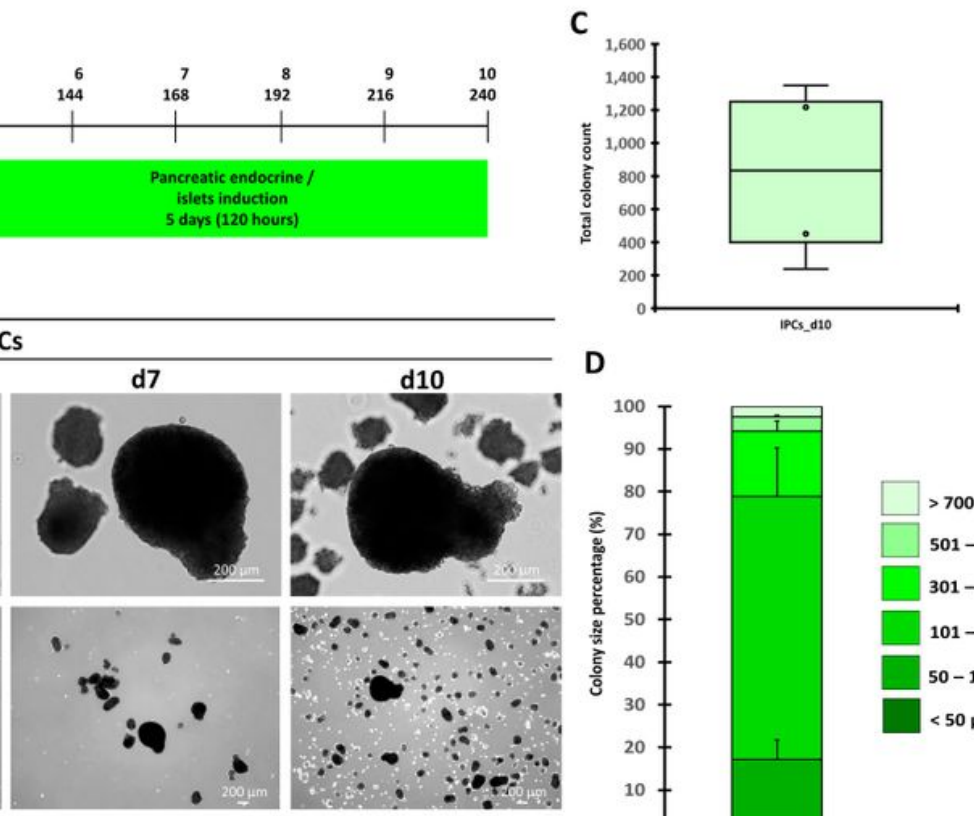

D

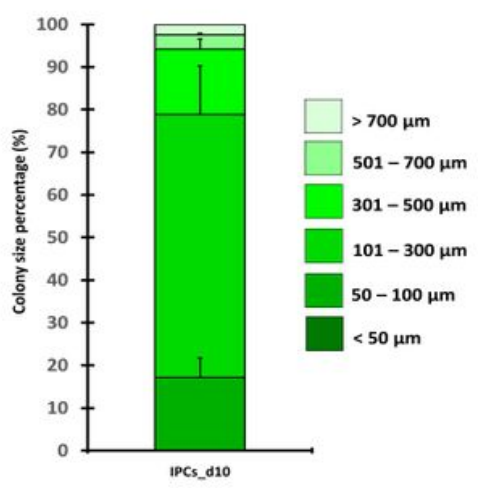

Glut-2
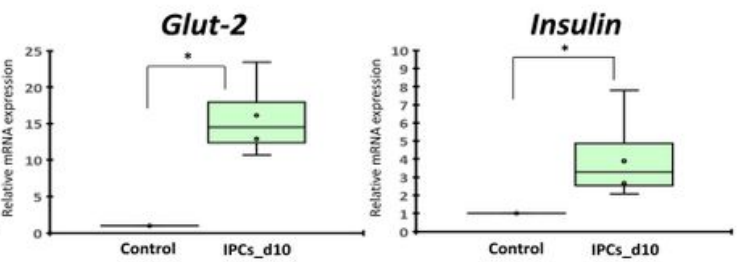

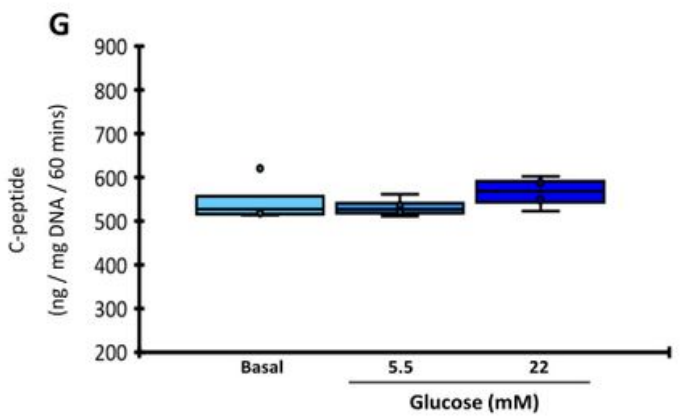




\section{Figure 5}

Generation of CAD-MSC-derived IPCs by microenvironmental manipulation. Diagram of culture technique used for the generation of CAD-MSC-derived IPCs was showed (A). Morphological appearances of cells undergone induction technique were observed under phase-contrast microscope with magnification of 40X and 200X (B). Total colony number (C) and colony size proportion (D) were evaluated. mRNA markers relating to pancreatic beta-cell $(\mathrm{E})$, and pancreatic-relating markers $(\mathrm{F})$ were analyzed by RTqPCR. mRNA expression was normalized with reference gene and undifferentiated control. Functional testing by glucose-stimulated C-peptide secretion (GSCS) was illustrated (G). Bars indicated significant difference $(*$, p-value $<0.05)$. 

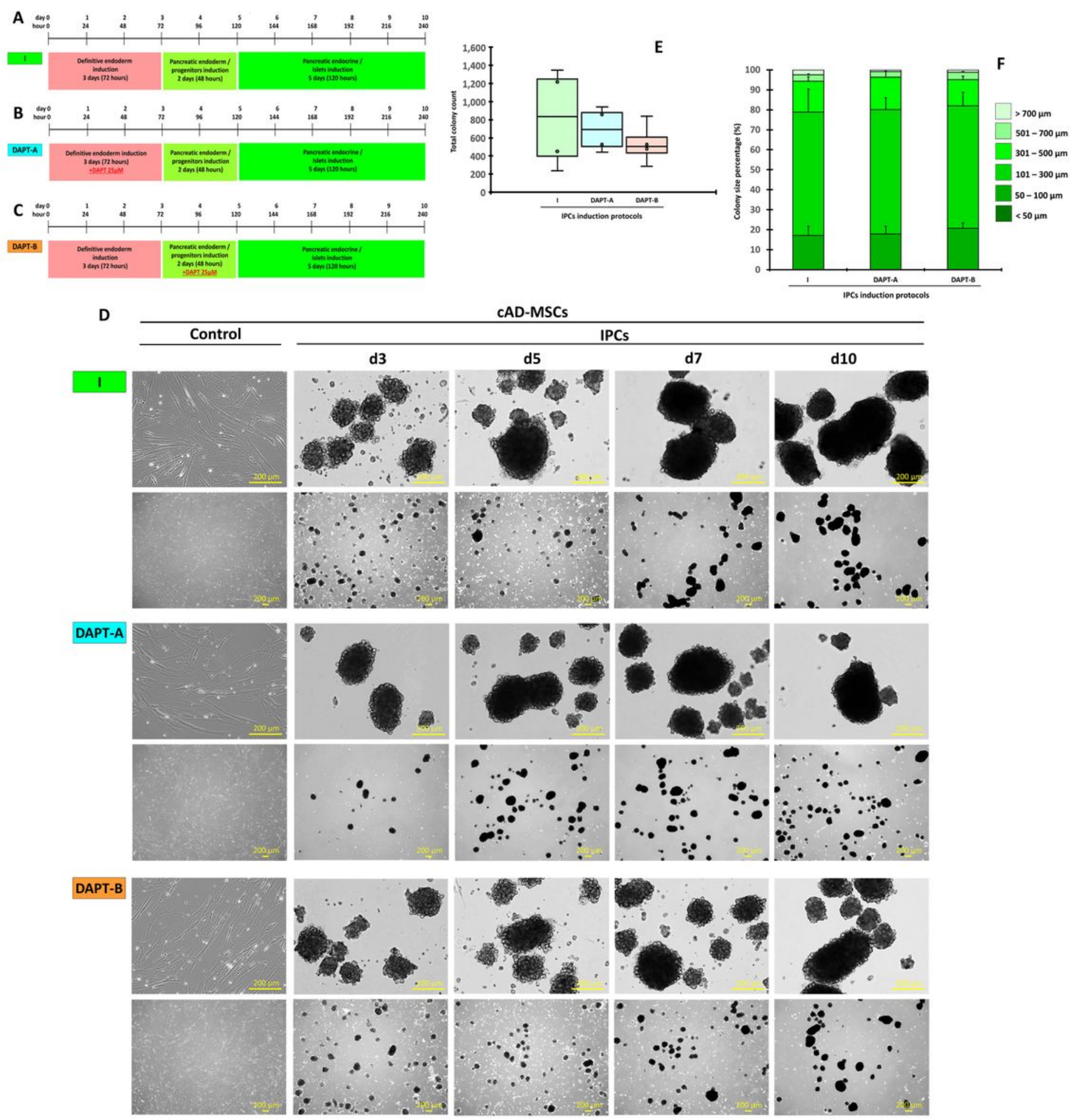

\section{Figure 6}

Generation of CAD-MSC-derived IPCs with Notch signaling manipulation. Diagrams of Notch signaling manipulation used for the generation of CAD-MSC-derived IPCs were showed (A-C). Morphological appearances of cells undergone each of induction technique were observed under phase-contrast microscope with magnification of 40X and 200X (D). Total colony number (E) and colony size proportion (F) were evaluated. 

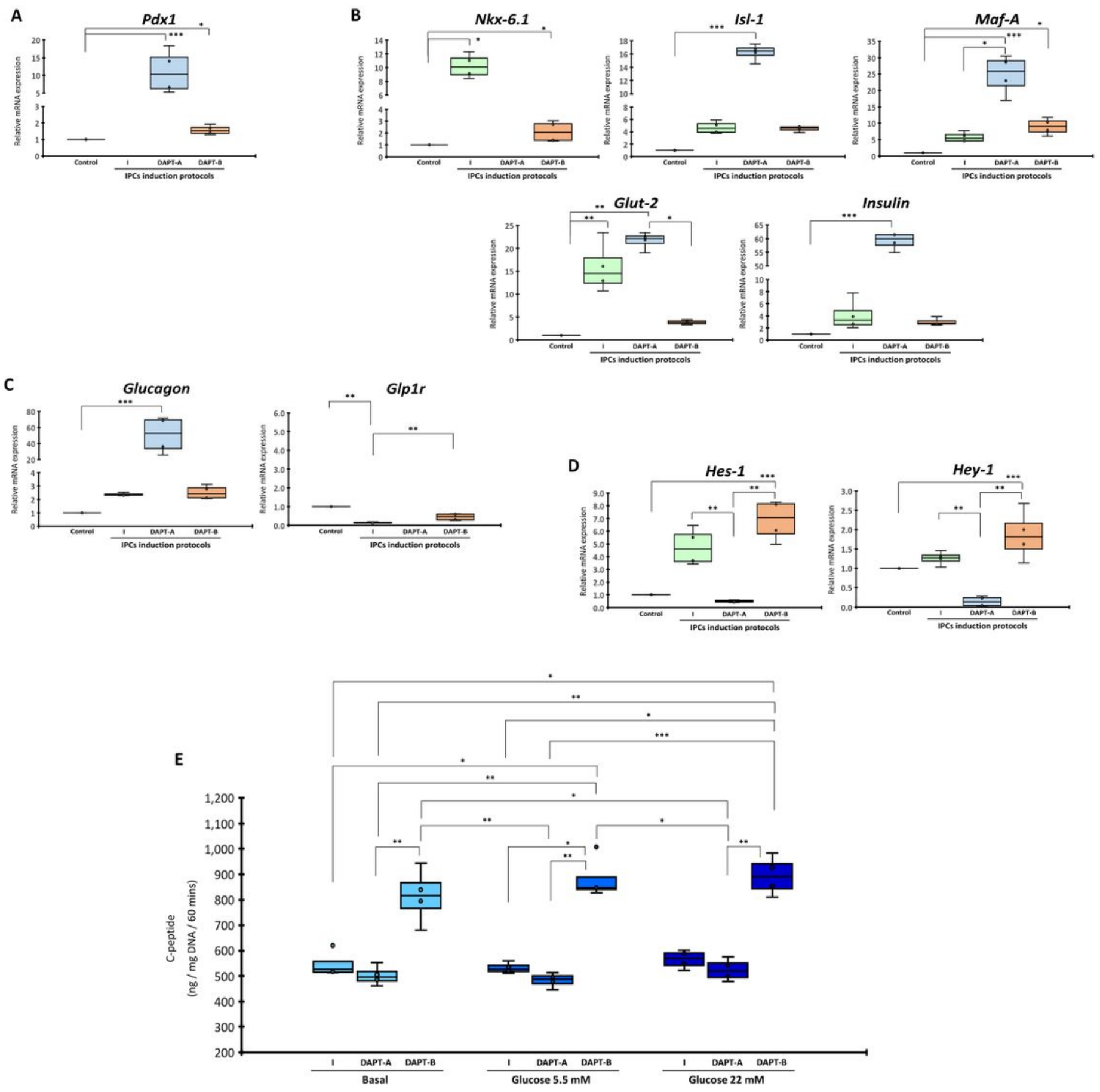

\section{Figure 7}

Generation of CAD-MSC-derived IPCs with Notch signaling manipulation. mRNA markers relating to pancreatic endoderm (A), pancreatic beta-cell (B), pancreatic-relating markers (C), and Notch target genes (D) were analyzed by RT-qPCR. mRNA expression was normalized with reference gene and undifferentiated control. Functional testing by glucose-stimulated C-peptide secretion (GSCS) was illustrated (E). Bars indicated significant difference (*, $p$-value $<0.05 ; * \star, p<0.01 ; * \star *, p<0.001)$. 


\section{Supplementary Files}

This is a list of supplementary files associated with this preprint. Click to download.

- 201203SupplementaryTableS1RodprasertetalScientificReports.pdf 